\title{
Proposta de método para análise de vulnerabilidade à erosão costeira no sudeste da ilha de Santa Catarina, Brasil
}

\author{
Alexandre M. Mazzer ${ }^{1,2}$, Sergio R. Dillenburg ${ }^{3}$ \& Célia R. de Gouveia Souza ${ }^{4}$
}

\begin{abstract}
Resumo A vulnerabilidade costeira à erosão está associada a diversos processos morfodinâmicos. Uma ampla gama de métodos é utilizada para analisar os seus níveis, em geral utilizando parâmetros geomorfológicos, taxas de variação da linha de costa, variações do nível do mar, altura de ondas etc. O presente trabalho propõe um método de análise de vulnerabilidade à erosão costeira para um trecho do sudeste da Ilha de Santa Catarina (SC), Brasil, utilizando como ferramenta de análise a compartimentação da linha de costa em células costeiras e modelagem espacial em sistema de informação geográfica. O método baseou-se em dois principais pressupostos: (1) as células costeiras são unidades homogêneas de balanço sedimentar; (2) os processos costeiros que atuam na linha de costa operam em diversas escalas temporais e, assim, podem produzir diferentes respostas quanto à vulnerabilidade costeira. A partir de oito variáveis ligadas à morfodinâmica costeira e duas taxas de variação da linha de costa em escalas interanual e interdecadal foram estabelecidos índices de vulnerabilidade costeira. Efetuou-se análise de risco das edificações situadas na orla em relação a um cenário de elevação do nível do mar. Os resultados demonstraram que a inclinação da face litorânea e a altura de ondas são variáveis importantes em ambas as escalas de análise. A distinção das análises entre escalas bem como, a abordagem utilizando unidades espaciais, remetem a subsídios para differentes ações de gerenciamento costeiro.
\end{abstract}

Palavras-chave: Vulnerabilidade costeira, Erosão Costeira, Orla Marítima, Escalas Temporais, Ilha de Santa Catarina.

\begin{abstract}
Methodological proposal to analyze coastal erosion vulnerability in southeast coast of Island of Santa Catarina, Brazil. Coastal vulnerability to erosion is associated to several coastal processes. A wide range of methods is used in order to determinate its levels along the shoreline. This paper presents a method of analyzing the vulnerability in a coastal stretch at the southeastern shore of the Santa Catarina Island (Santa Catarina State, Brazil), through the use of coastal cells and a spatial modeling in a Geographic Information System. The method is based on two presuppositions as follows: (1) coastal cells are homogeneous units of sedimentary budget; (2) coastal processes occur at several spatial and temporal scales, and may lead to different shoreline responses. Through eight variables linked to coastal morphodynamic processes combined by linear aggregation with two shoreline changes rates, in interdecadal and interannual scales, a coastal vulnerability index was established. Results demonstrated that the most important variables were the shoreface slope and the wave height in relation to both scales of shoreline changing rates. The distinction between temporal scales as well as the use of spatial units are developed to support different coastal management actions.
\end{abstract}

Keywords: Coastal vulnerability, Coastal erosion, Aseashore unit, Temporal Scales, Santa Catarina Islands.

INTRODUÇÃO A orla marítima representa uma unidade geográfica especialmente vulnerável a fenômenos naturais ligados à dinâmica costeira, denotados por processos de erosão e deposição praial, inundação costeira, incidência de ventos intensos, marés meteorológicas entre outros. No entanto, diante da complexa interação dessas variáveis, a orla marítima pode apresentar características distintas em sua extensão, dada por feições geomórficas costeiras representadas por diferentes tipos de praias, dunas e desembocaduras. Tal distinção e complexidade remetem à ocorrência de trechos costeiros que apresentam diferentes respostas aos processos naturais e atividades antrópicas, em relação à erosão costeira.

A erosão costeira é um fenômeno mundial (Bird 1985), e também predomina na costa brasileira (Souza et al. 2005, Muehe 2006), estando relacionada à elevação do nível do mar ou não, ocasiona efeitos que remetem à vulnerabilidade costeira.

A vulnerabilidade representa um arranjo de atributos ou variáveis que caracterizam maior fragilidade, fraqueza ou passividade em relação à incidência de um evento/ fenômeno de alta energia ou de potencial destrutivo, no

1- Departamento de Geografia, Universidade da Região de Joinville, Joinville (SC), Brasil. E-mail: alexandre.mazzer@univille.net

2 - Programa de Pós-Graduação, Centro de Estudos de Geologia Costeira e Oceânica-CECO, Universidade Federal do Rio Grande do Sul, Porto Alegre (RS), Brasil.

3 - Centro de Estudos de Geologia Costeira e Oceânica-CECO, Universidade Federal do Rio Grande do Sul, Porto Alegre (RS), Brasil.

E-mail: sergio.dillenburg@ufrgs.br

4 - Instituto Geológico, Secretaria de Estado de Meio Ambiente de São Paulo, São Paulo (SP), Brasil. E-mail: celia@igeologico.sp.gov.br 
caso a erosão costeira (Dal Cin \& Simeoni 1994, Klein \& Nicholls 1999, Hennecke \& Cowell 2000, Cobum 2001),

Nicholls (1995) realizou extensa revisão sobre estudos de vulnerabilidade costeira frente à elevação do nível do mar, realizados em 22 países, estimando cerca de 180 milhões de pessoas afetadas por este fenômeno, além da perda de $150.000 \mathrm{Km}^{2}$ de terra emersa. A relação ente a elevação do nível do mar e a erosão costeira é consenso na literatura, destacando o trabalho pioneiro de Brunn (1962).

A maior parte dos trabalhos contemporâneos sobre vulnerabilidade costeira é realizada através da modelagem de variáveis, sendo que, para tanto, são utilizados Sistemas de Informação Geográfica (SIGs) (Cooper \& Mc Laughlin 1998). No entanto, ocorre grande diferença em relação às variáveis utilizadas, sendo este um fator diretamente dependente da escala de trabalho, do fenômeno em questão (erosão costeira, inundação costeira, elevação do nível do mar, entre outros) e das características de cada área estudada. Em muitos casos foram efetuadas determinações de variáveis, bem como parametrizações das mesmas através de métodos já estabelecidos na literatura (Gornitz et al. 1992, Dal Cin \& Simeoni 1994), tais como determinação de variação de linha de costa por fotos aéreas e cálculos de taxas de transporte sedimentar, entre outros. Tal fato reflete a necessidade de se obter tais valores para análises desta natureza. No entanto, muitas vezes, é difícil a disponibilidade de alguns tipos de dados para certas localidades/regiões.

No Brasil, a orla marítima tem merecido atenção especial quanto ao regime de uso e ocupação, o qual é regulamentado pelo Decreto $n^{\circ}$ 5.300/04 e MMA (2006), que estabelece um conjunto de ações que constituem o chamado "Projeto Orla". Neste projeto, são mencionados quais são os aspectos morfodinâmicos, características de transporte de sedimentos e, sobretu- do, quais dados relativos à erosão costeira que devem ser considerados para o planejamento e intervenções antrópicas na orla. No entanto, mesmo existindo um arcabouço legal que considere a importância de aspectos geológicos costeiros, a aplicação dos princípios técnicos pode não ser efetiva no sentido de abranger fenômenos de erosão costeira no planejamento.

Portanto, faz-se mister levantar a importância da inserção dos conceitos de balanço sedimentar e escalas espaço-temporais de processos costeiros nas ações de planejamento e gerenciamento costeiro, sobretudo, naquelas que remetem à aplicação do "Projeto Orla" nos municípios costeiros, as quais estão relacionadas as décadas e séculos.

No presente trabalho é apresentado um método de análise da vulnerabilidade costeira quanto à erosão, fundamentado em uma análise que envolve duas escalas temporais e a relação espacial dos conceitos de orla marítima e células costeiras.

A área-piloto abrange cinco praias arenosas localizadas no sudeste da Ilha de Santa Catarina, município de Florianópolis, Santa Catarina, Brasil. Esse trecho possui três compartimentos costeiros (Mazzer 2007) que apesar de estarem associados ao mesmo sistema deposicional, exibem características morfodinâmicas distintas. Procedeu-se a uma comparação entre variáveis relacionadas à linha de costa sob a perspectiva da variação da linha de costa em escalas interanual e interdecadal, e dentro do contexto do balanço sedimentar em cada compartimento costeiro.

ÁREA DE ESTUDO A Ilha de Santa Catarina possui $431 \mathrm{~km}^{2}$ de área total, apresentando formato alongado, com orientação geral NE-SW e distando cerca de 600 metros do continente (Fig. 1).

No contexto geomorfológico, a região se enquadra no Litoral de Escarpas Cristalinas (Silveira 1964), o

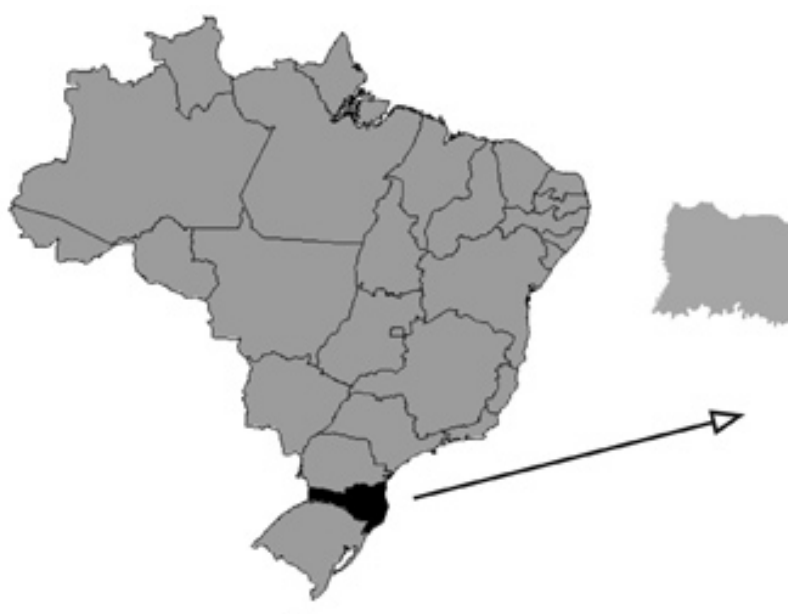

A)

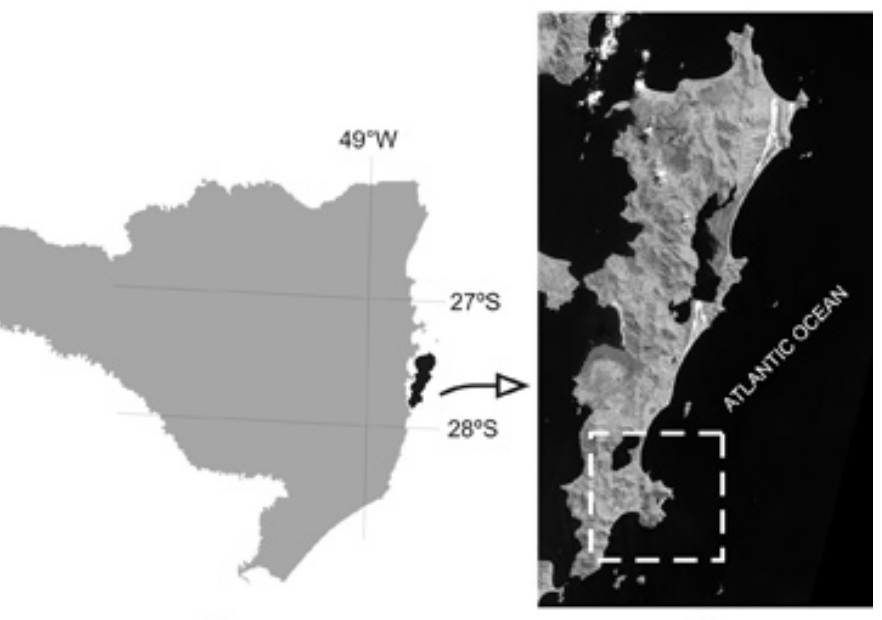

B)

C)

Figura 1 - Contexto geográfico da área de estudo (quadro tracejado na cor branca): (A) Brasil, (B) Estado de Santa Catarina, (C) Ilha de Santa Catarina. 
qual se caracteriza pela presença de serras costeiras, ocasionando um relevo com maiores amplitudes altimétricas, onde se denotam feições de pontões, morros alinhados e isolados, vales e sulcos estruturais, promontórios rochosos, e uma configuração litorânea com a presença de enseadas, baías, penínsulas, sacos e ilhas costeiras.

Em termos geotectônicos, a região está inscrita na Plataforma de Florianópolis, que consiste no alto estrutural do escudo catarinense, conforme Caruso Jr. (1993). Na Ilha de Santa Catarina, as rochas do embasamento cristalino são formadas na maior parte por granitóides gerados no evento termo-tectônico do Período Cambriano conhecido por Ciclo Brasiliano. Ocorrem também rochas intrusivas básicas, na forma de diques de diabásio, originados do magmatismo associado à separação entre os continentes sul-americano e africano, no período Jurássico-Cretáceo (Zanini et al. 1997).

A planície costeira é constituída por depósitos sedimentares relacionados a dois principais sistemas deposicionais: Leques Aluviais e Laguna-Barreira. Este último, de especial importância para o presente trabalho, é caracterizado por depósitos sedimentares geneticamente associados a processos costeiros e às variações do nível relativo do mar durante o Quaternário. São representados por depósitos praiais, eólicos, lagunares e paludiais (Caruso Jr. 1993), configurando feições de barreiras arenosas, lagunas, lagoas costeiras, dunas ativas e inativas, planícies de cristas praiais e áreas alagadiças associadas a manguezais, apicuns, marismas e canais de maré (Rosa \& Herrman 1986).

Na Plataforma Continental adjacente, a quebra para o talude continental ocorre entre 140 e 170 metros de profundidade. A isóbata de 30 metros situa-se a aproximadamente $10 \mathrm{~km}$ da linha de costa, definindo um gradiente geral para a área de estudo de aproximadamente $0,3 \%$. Este gradiente é maior no trecho leste e menor no trecho sul da área de estudo.

O clima do litoral catarinense caracteriza-se por sua exposição às influências do clima temperado meridional, subtropical e tropical, caracterizando uma zona de transição climática (Nimer 1979). Dados climáticos referentes à Ilha de Santa Catarina indicam tempera- tura média anual de $21,5^{\circ}$ e precipitação média anual de $1492 \mathrm{~mm}$. Os ventos apresentam velocidade média de $3,31 \mathrm{~m} / \mathrm{s}$, sendo os de direção norte e nordeste os mais freqüentes (cerca de $47 \%$ ), e os de quadrante sul os mais intensos (cerca de 32,5\%), alcançando até 6,50 $\mathrm{m} / \mathrm{s}$ (Porto F ${ }^{\circ}$ 1993).

Tais características climáticas ocorrem pela influência de quatro principais sistemas atmosféricos: Baixa Pressão Móvel Polar, Anticiclone do Atlântico Sul, Anticiclone do Pacífico Sul e Centro de Baixa Pressão do "Chaco" (Bigarella et al. 1994). Tais sistemas associam-se aos principais eventos meteorológicos, os quais apresentam influência direta nos processos morfodinâmicos da linha de costa, na forma da geração de ondas marítimas e de marés meteorológicas. Essa influência se dá através de três mecanismos: sistemas frontais, ciclones extra tropicais e atuação semi-permanente do sistema de alta pressão, denominado de Anticiclone do Oceano Atlântico Sul. Os dois primeiros mecanismos apresentam amplos gradientes de pressão atmosférica, gerando conseqüentemente ventos de forte intensidade do quadrante sul, enquanto o anticiclone ocorre em caráter semi-permanente, mas representa $80 \%$ das ocorrências na zona costeira catarinense ao longo do ano (Porto $\mathrm{F}^{\circ} 1993$ ).

As informações sobre o clima de ondas utilizadas neste trabalho foram obtidas a partir de uma série histórica de observações realizadas em embarcações (Hogben et al. 1986), e com base em dois anos de dados médios obtidos por ondógrafo tipo "Wave Rider" disponível em Araújo et al. (2003) e sumarizados por Mazzer et al. (submetido), conforme mostra a tabela 1.

O presente estudo abrange cinco praias localizadas no sudeste da Ilha de Santa Catarina, que totalizam 9,2 km de linha de costa arenosa (Fig. 2), conforme descrito a seguir.

Praia da Solidão A praia da Solidão é uma típica praia de bolso, que se estende por $1.345 \mathrm{~m}$, em orientação NESW. Seu estagio morfodinâmico é do tipo dissipativo, apresentando um grau médio de exposição às ondas $\mathrm{e}$

Tabela 1 - Dados sobre os principais tipos de ondas ocorrentes na região do Litoral de Santa Catarina.

\begin{tabular}{|c|c|c|c|c|c|c|c|c|c|}
\hline \multirow[t]{2}{*}{ Denominação } & \multirow{2}{*}{$\begin{array}{c}\text { Direção } \\
\text { em águas } \\
\text { profundas }(\theta)^{1}\end{array}$} & \multirow{2}{*}{$\begin{array}{l}\text { Período de } \\
\text { Pico }\left(\mathrm{T}_{\mathrm{p}}\right)^{1}\end{array}$} & \multirow{2}{*}{$\begin{array}{c}\text { Tamanho } \\
\text { significativo de } \\
\text { onda }\left(\mathrm{H}_{\mathrm{S}}\right)^{1}\end{array}$} & \multirow[t]{2}{*}{$\begin{array}{l}\mathrm{Fr} * \\
(\%)^{2}\end{array}$} & \multicolumn{5}{|c|}{$\begin{array}{c}\text { Freqüência }(\%) \\
\text { por intervalo de altura de onda }\end{array}$} \\
\hline & & & & & $0-1 \mathrm{~m}$ & $1-2 m$ & $2-3 m$ & $3-4 m$ & $4-5 m$ \\
\hline Ondulação de Sul & $162^{\circ}$ & $11,4 \mathrm{~s}$ & 1,25 a $2,0 \mathrm{~m}$ & 11 & 13,8 & 38,0 & 27,8 & 12,7 & 4,8 \\
\hline $\begin{array}{l}\text { Ondulação de } \\
\text { Sudeste }\end{array}$ & $146^{\circ}$ & $14,2 \mathrm{~s}$ & 1,50 a $2,0 \mathrm{~m}$ & 16 & 19,4 & 40,5 & 24,6 & 9,9 & 3,5 \\
\hline Ondulação de Leste & $92^{\circ}$ & $8,5 \mathrm{~s}$ & 0,75 e $1,75 \mathrm{~m}$ & 10 & 22,2 & 42,0 & 23,0 & 8,5 & $>3,0$ \\
\hline Vagas de nordeste & $27^{\circ}$ & $4,5 \mathrm{~s}$ & $>0,75 \mathrm{~m}$ & 20,5 & 23,9 & 43,2 & 21,8 & 7,5 & $>3,0$ \\
\hline Vagas de Sul & $188^{\circ}$ & $7,7 \mathrm{~s}$ & $>1,0 \mathrm{~m}$ & 10 & & & & & \\
\hline
\end{tabular}




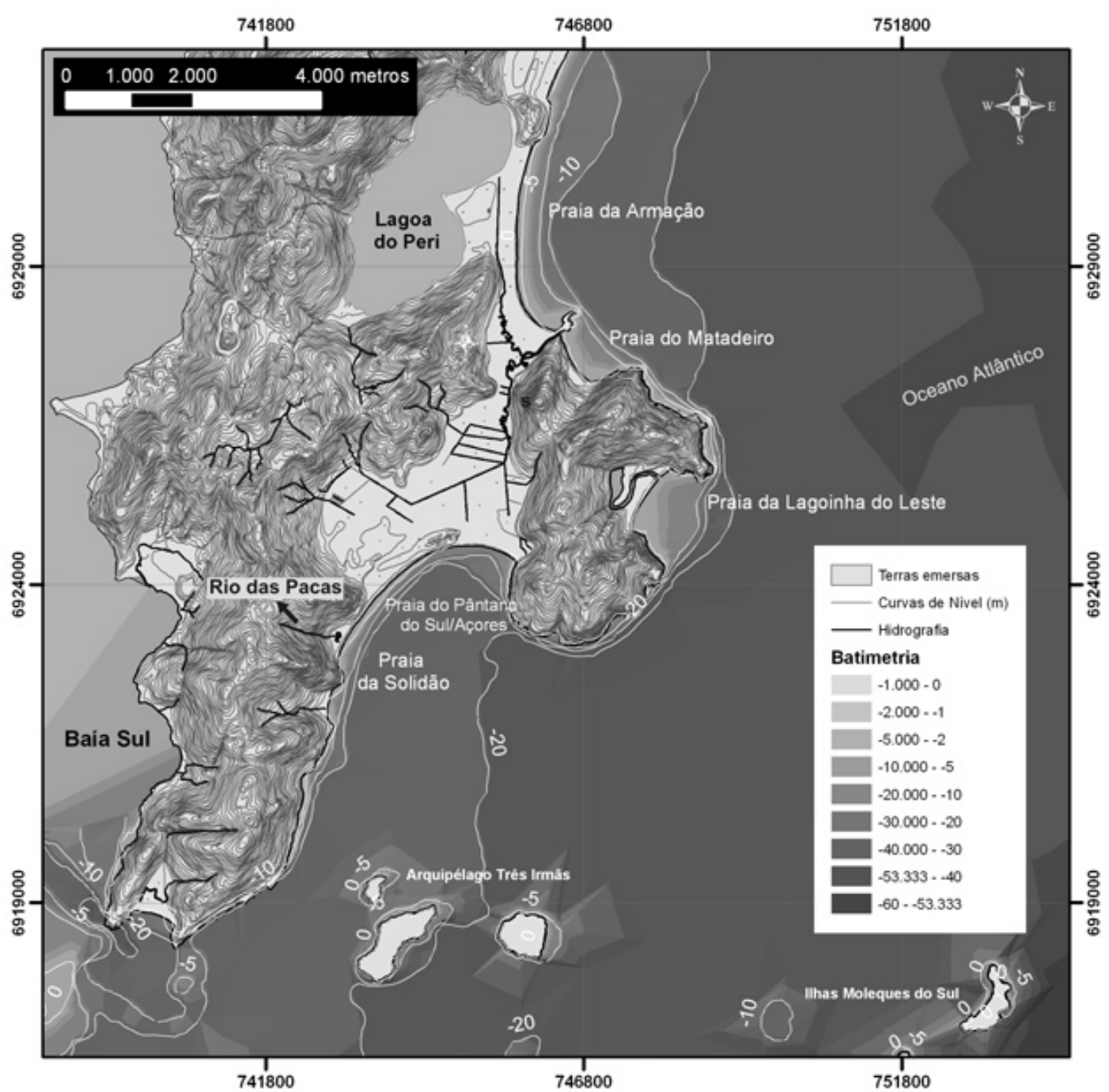

Figura 2 - Localização e algumas características fisiográficas da área de estudo.

um nível alto de ocupação antrópica (Mazzer 2004).

Praia do Pântano do Sul/Açores As praias do Pântano do Sul e dos Açores são denominações locais para um mesmo arco praial de orientação ENE-WSW, com extensão total de cerca de $2.100 \mathrm{~m}$. Configura-se como uma enseada do tipo baía em espiral (Mazzer 2004), a qual consiste de um arco côncavo com intensificação da curvatura da linha de costa na extremidade leste, onde se desenvolvem distintos graus de exposição às ondulações de leste, sudeste e sul, apesentando estágios morfodinâmicos intemediários (Oliveira 2004). Possui alto nível ocupação antrópica no extremo leste, na localidade de Pântano do Sul, e na porção central, na localidade denominada de praia dos Açores (Mazzer op. cit, Oliveira 2004).

Praia da Lagoinha do Leste A praia da Lagoinha do Leste possui orientação NNE-SSW e cerca de $1200 \mathrm{~m}$ de extensão. Apresenta-se com estágios morfodinâmicos de dissipativo à intermediário, estando submetida a um regime de alta energia. É uma das praias mais expostas às ondulações (todas as direções) da Ilha de Santa Catarina. Encravada num promontório rochoso, apresenta ocupação antrópica permanente praticamente ausente, também porque está inserida em uma unidade de conservação, o Parque Municipal da Lagoinha do Leste.

Praia do Matadeiro A praia do Matadeiro é guarnecida por promontórios rochosos, apresentando no seu extremo norte a desembocadura do Rio do Peri. Sua linha de costa está orientada no sentido NW-SE, com extensão de 1.200 $\mathrm{m}$. Apresenta perfil praial dissipativo em condições semiabrigadas, estando protegida das ondulações do quadrante sul. Contudo, encontra-se exposta às ondulações de leste e às vagas de nordeste. A ocupação na orla pode ser considerada de nível médio a alto (Mazzer 2004).

Praia da Armação A praia da Armação é limitada pelo promontório rochoso do Morro das Pedras ao norte, e pelo tômbolo formado entre a praia e a Ilha das Campanhas, na porção sul, formando uma enseada (embaíamento) em espiral. Estende-se por cerca de 3.500 metros, orientada no sentido N-S, e apresenta-se com estágio 
refletivo ao norte passando a intermediário na porção central, e a dissipativo ao sul (Castilhos 1995). Consiste numa praia exposta às ondulações dos quadrantes leste $\mathrm{e}$ sul e apresenta um nível de ocupação passando de ausente a alto no sentido norte-sul (Mazzer 2004).

\section{MATERIAIS E MÉTODOS}

\section{Pressupostos metodológicos}

\section{UNIDADE ESPACIAL OU GEOGRÁFICA}

Células Costeiras e Balanço Sedimentar O balanço sedimentar negativo nas praias, decorrente de processos naturais e/ou intervenções antrópicas constitui uma das principais causas de erosão costeira no Brasil (Souza \& Suguio 2003, Muehe 2006).

Assim, no presente trabalho, adotou-se o conceito de célula costeira como unidade básica de análise de vulnerabilidade à erosão, uma vez que ela representa uma unidade de balanço sedimentar (Griggs 1987, Carter 1988, Bray et al. 1995, Cooper et al. 2001).

A definição espacial das células costeiras na área de estudo, foi realizada por Mazzer (2007), a partir de diagramas de refração e difração de onda e características praias relativas à morfologia e textura sedimentar

Orla Marítima Orla marítima é definida pelo MMA (2006) como "unidade geográfica inclusa na zona costeira, delimitada pela faixa de interface entre terra firme e o mar, caracterizada pelo equilíbrio dinâmico onde interagem processos geológicos e oceanográficos, entre outros" (Muehe 2001). Seu significado em Ferreira (2004) remete a bordo, rebordo, margem, faixa (...), o que permite uma abertura quanto aos critérios de enquadramento. A delimitação da orla marítima, conforme Brasil (2004) inclui a faixa terrestre de $50 \mathrm{~m}$ a partir da linha de vegetação para as áreas urbanas consolidadas, e $200 \mathrm{~m}$ para urbanização moderada ou inexistente; e, na faixa marítima, a isóbata de $10 \mathrm{~m}$, considerada a profundidade de fechamento média para as praias brasileiras (Muehe 2001).

Assim, para a delimitação da linha de costa na área de estudo, adotou-se uma faixa de $50 \mathrm{~m}$ da retro-terra adicionada ao perfil emerso das praias que, combinadas com as células costeiras, formam as unidades espaciais/ geográficas de análise da vulnerabilidade costeira, aqui denominadas Unidades de Orla Marítima (OM) (Fig. 3). A escala de espacialização foi de 1:10.000.

ANÁLISE MULTIESCALONADA A dinâmica da linha de costa está relacionada com agentes costeiros (ondas, marés etc.) que variam ao longo de dias, semanas, meses, estações, anos, décadas, séculos e milênios (Carter 1988, Camfield \& Morang 1996, Stive et al. 2002), e estes agentes, em estreita combinação com a quantidade de sedimentos disponível no sistema costeiro, determinam a configuração da linha de costa e da planície costeira (Cowell \& Thom 1995). Tais aspectos foram incluídos na metodologia da presente análise de forma que cada processo e seus respectivos domínios espaço-temporais contribuam de forma distinta em relação a sua escala de abrangência na erosão costeira. Assim sendo, os proces- sos estão representados por diferentes pesos na análise final de vulnerabilidade costeira.

Base de dados Os dados e informações foram modelados e organizados em um SIG, utilizando o programa Arc Info 9.1 Desktop e seu elenco de ferramentas de digitalização, manipulação, conversão, edição, análise e modelagem espacial disponível no módulo Arc Toolbox e suas extensões.

Os dados constituintes do SIG podem ser separados em três categorias: (1) base cartográfica; (2) análise espacial; e (3) compilação de dados disponíveis na literatura e espacialização dos mesmos.

(1) A base cartográfica elaborada para este trabalho inclui: topografia com curvas de nível em intervalos de $5 \mathrm{~m}$, em arquivos de polilinhas obtidos em cartas topográficas de escala 1:10.000 (IPUF 1979); malha de pontos cotados via levantamento planialtimétrico em arquivo vetorial de escala 1:2.000 (IPUF 2002); e dados batimétricos proveniente das cartas náuticas $n^{\circ}$ 1902 e 1904 da Diretoria de Hidrografia e Navegação da Marinha do Brasil (escala 1:49.927), as quais foram escaneadas, georeferenciadas e posteriormente digitalizadas no modo on screen nas extensões Editing e $A d-$ vanced Editing do programa Arc Info 9.1, constituindo arquivos de pontos (para os pontos batimétricos) e polilinhas (para isóbatas). Além desses, compõem a base cartográfica os componentes de imagens: série temporal de levantamentos aerofotogramétricos dos anos de 1938, 1978, 1994 e 1998 (escalas entre 1:30.000 a 1:8.000) e um conjunto de ortofotos do ano de 2002, escala 1:2.000 (IPUF 2002), previamente organizados em Mazzer \& Dillenburg (submetido).

(2) As análises espaciais de dados da base cartográfica efetuadas em ambiente SIG, e que foram necessárias na análise da vulnerabilidade foram: (a) modelo numérico de terreno (MNT) utilizando o modelo de triangulação irregular e o TOPOGRID, abrangendo os dados de cartografia e batimetria supracitados, os quais permitiram obter dados contínuos das cotas da superfície; (b) extração de perfis batimétricos; (c) decomposição e equacionamento de dados de altura e direção de ondas, a partir de modelagem de refração-difração de ondas realizadas no programa MIKE 21 (Mazzer 2007); (d) mapeamento de feições litorâneas erosivas e da ocupação antrópica a partir de fotointerpretação nos conjuntos de fotografias aéreas e inspeção de campo com a ajuda de GPS Garmin 12, trena e clinômetro; (e) análise da distância da ocupação antrópica a partir do comando minimum distance do Arc Toolbox; (f) orientação da linha de costa, determinação do ângulo azimutal de cada célula costeira e sua exposição às quatro principais direções de ondulação atuantes na área de estudo (E, S, SE e NE).

(3) A compilação de dados disponíveis para a área incluiu conteúdos relativos a processos erosivos e estágio morfodinâmico (Grê et al. 1997, Castilhos 1995, Oliveira 2004); granulometria e perfil praial (Miott 2004, Oliveira 2005), taxas de variação em escala interdecadal e interanual (Mazzer \& Dillenburg, submetido), clima de ondas (Hogben et al. 1986, Araú- 


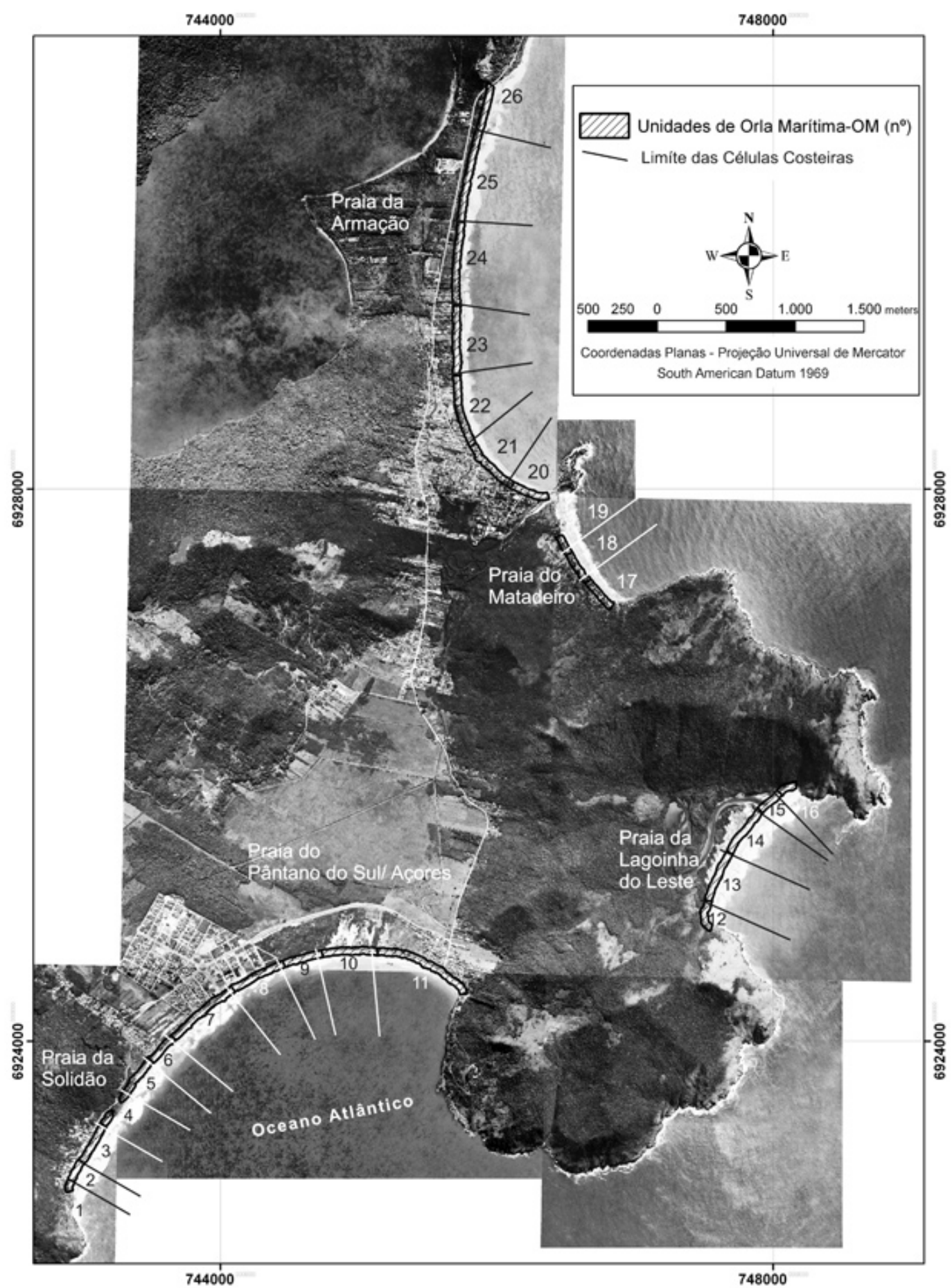

Figura 3 - Unidade de Orla Marítima (OM), com limites correspondentes às células costeiras.

jo et al. 2003), além de informações indiretas que, embora não tenham sido espacializadas, contribuíram para a análise e validação da modelação dos dados.

Variáveis utilizadas Certamente a escolha de variáveis é um dos principais eixos metodológicos dos trabalhos sobre vulnerabilidade costeira. Porém, nem sempre o maior número de variáveis leva a uma melhor análise (Cooper \& McLaughin 1998), sendo que muitas dessas variáveis podem ter efeitos similares, ou mesmo serem irrelevantes e estarem tomando lugar de outras importantes.

Foram consideradas dez variáveis no presente trabalho, todas relacionadas com processos hidrodinâmicos e morfodinâmicos da linha de costa, A escolha preliminar das mesmas baseou-se na bibliografia revisada, destacando as obras de Bird (1985), Gornitz et al. (1992), Dal Cin \& Simeoni (1994), Bush et al. (1996), 
Cooper \& Mc Laughin (1998), Perillo et al. (1999), Thumerer et al. (2000), Titus \& Richman (2001), Souza \& Suguio (2003), Mazzer (2004) e Menezes \& Klein (2004) e Muehe (2006).

As 10 variáveis ligadas à morfodinâmica da linha de costa e à hidrodinâmica da face litorânea (shoreface): taxa de variação de linha de costa interanual, taxa de variação de linha de costa interdecadal, altura de onda na quebra; amplitude altimétrica da orla marítima, inclinação da face litorânea, velocidade residual de corrente longitudinal, balanço sedimentar potencial, largura média da pós-praia, tamanho médio de grão no estirâncio e inclinação média da praia no estirâncio.

Diversos trabalhos sobre vulnerabilidade costeira consideram como variável mais importante a taxa de variação da linha de costa (Gornitz et al. 1992, Dal Cin \& Simeoni 1994, Bush et al. 1996, Cobum 2001).

As variáveis de inclinação de antepraia, e aporte sedimentar via fluvial, foram as que mais estavam associadas às áreas de maior vulnerabilidade a erosão costeira, na costa de Marche, Itália, Dal Cin \& Simeoni (1994). A inclinação apresenta-se diretamente relacionada a processos de quebra de onda e correntes longitudinais, e outros indicadores como declividade do esirâncio, largura média de pós-praia, além das taxas de erosão

$\mathrm{O}$ uso de dados de sedimentos praiais para interpretar processos litorâneos são bastante utilizados na geologia costeira, como por exemplo as contribuições de Brunn (1962), Dubois (1982), Bird (1985), entre outras, as quais sugerem a relação entre mudanças granulométricas no ambiente praial, erosão costeira e elevação do nível do mar. No Brasil, Souza (1997), Souza \& Suguio (2003) e Souza (2007) trabalharam com parâmetros granulométricos como indicadores de processos erosivos e de análise de risco no litoral do estado de São Paulo.

A escala local de análise (1:10.000) também contribuiu para selecionar apenas aquelas variáveis de magnitude condizente à dinâmica da linha de costa nesta escala, a fim de relacioná-las com o objeto do trabalho: a orla marítima. Deste modo baseou-se em Carter (1988) e Stive et al. (2002) para definir o límite espaço temporal da análise em: dezenas à centenas de metros no plano espacial, e, anual até secular na escala temporal.

Conforme mencionado nos pressupostos I e II, as variáveis foram discretizadas pela média de suas ocorrências em cada célula costeiras e representadas nas OM. (Fig. 3)

As formas de obtenção das variáveis, assim como os tratamentos metodológicos prévios, foram bastante diversificados, conforme segue abaixo.

TAXAS DE VARIAÇÃO DA LINHA DE COSTA INTERANUAL (TXA) E INTERDECADAL (TXD) A variação temporal da linha de costa é expressa em duas escalas: interanual (TXA) e interdecadal (TXD) (Mazzer \& Dillenburg, submetido). A primeira foi efetuada com dados obtidos de fotografias aéreas, provenientes dos anos de 1998 a 2002, pelo método End Point Rate (Dolan et al. 1991). Na variação em escala interdecadal foram tomadas medidas da linha de costa nas aerofotos dos anos de 1938, 1978, 1994, 1998 e 2002 e, então, calculou-se a taxa de variação por regressão linear iterativa (Jacknife method - Dolan et al. 1991).

ALTURA DE ONDA (HB) Dados de onda em águas profundas foram obtidos em Araújo et al. (2003), para três condições monocromáticas de ondulação ("swell") mais freqüentes (Tab. 1). A partir de tais dados foi obtido, através do programa MIKE 21 PMS, um diagrama de refração-difração de ondas (Mazzer et al., submetido), o qual permitiu o cálculo da altura de onda a partir da equação 1:

$$
\begin{aligned}
& \mathrm{H}_{\mathrm{b}}=\mathrm{H}_{0} /(0.563) /\left(\mathrm{H}_{0} / \mathrm{L}_{0}\right) \\
& \text { (CERC 1984) }
\end{aligned}
$$

INCLINAÇÃO DA FACE LITORÂNEA (IFL) A determinação da inclinação da face litorânea (shoreface) foi precedida da definição do limite da mesma pelo cálculo da profundidade de fechamento média para cada praia, pela equação 2

$$
\begin{aligned}
& \mathrm{d}=2 \mathrm{H}_{\mathrm{s}}+11 \sigma \\
& \text { (Hallermeyer } 1981 \text { apud Muehe 2001) }
\end{aligned}
$$

Com dados de onda de Araújo et al. (2003) foram obtidos valores entre 9,30 metros e $11,50 \mathrm{~m}$, o que levou a uma média geral e generalização em 10 metros, corroborando o determinado por Muehe (2001) para a costa brasileira.

Foram traçados perfis perpendiculares à linha de costa sobre o modelo numérico de terreno, até a isóbata de 10 metros, os quais permitiram o cálculo de sua declividade média, automatizada na extensão Surface Tools do programa Arc View 3.2. (Fig. 3 e Tab. 2).

AMPLITUDE ALTIMÉTRICA DA ORLA MARÍTIMA (ALT) Os dados referentes à altimetria da orla marítima foram extraídos do modelo numérico de terreno (MNT), a partir do recorte deste, com cada polígono representando as células costeiras. A altimetria representa a predisposição em dimensão vertical que a OM irá apresentar frente a um recuo da linha de costa, além de estar associada a suscetibilidade a inundação costeira (Souza 2004). Para cada célula costeira foi estimada a média e máxima da altitude através da sumarização dos dados altimétricos tabulares, sendo a última utilizada no equacionamento do perfil de equilíbrio.

VELOCIDADE RESIDUAL DE CORRENTE LONGITUDINAL (CLR) A velocidade média de correntes longitudinais para as células costeiras da área de estudo foi obtida para três ondulações (Tab. 1) (Mazzer 2007, Mazzer et al. submetido). As correntes residuais foram obtidas a partir da redução da velocidade média de corrente de cada célula costeira, através da multiplicação por pesos obtidos a partir da freqüência relativa entre essas ondulações. (adaptado de Hogben et al. 1986) (Tab. 1). Posteriormente, os valores foram somados para determinar o valor relativo residual da 
Tabela 2 - Variáveis utilizadas na análise de vulnerabilidade costeira.

\begin{tabular}{|c|c|c|c|c|c|c|c|c|c|c|c|c|c|}
\hline $\begin{array}{c}\mathrm{OM} \\
\mathrm{N}^{\mathrm{o}}\end{array}$ & $\begin{array}{c}\text { Taxas } \\
\text { de variação } \\
\text { interanual } \\
\text { (m/ano) }\end{array}$ & $\begin{array}{c}\text { Taxas } \\
\text { de } \\
\text { variação } \\
\text { interdecadal } \\
\text { (m/ano) }\end{array}$ & $\begin{array}{c}\text { Altura } \\
\text { de Onda } \\
\left(\mathrm{H}_{\mathrm{b}}\right) \\
(\mathrm{m})\end{array}$ & $\begin{array}{c}\text { Inclinação } \\
\text { de face lit. } \\
\left(^{\circ}\right)\end{array}$ & $\begin{array}{c}\text { Altitude } \\
(\mathrm{m})\end{array}$ & $\begin{array}{c}\text { Corrente } \\
\text { residual } \\
(\mathrm{m} / \mathrm{s})\end{array}$ & $\begin{array}{l}\text { Tamanho } \\
\text { de grão no } \\
\text { estirâncio } \\
(\varphi)\end{array}$ & $\begin{array}{c}\text { Inclinação } \\
\text { de } \\
\text { estirâncio } \\
\left({ }^{\circ}\right)\end{array}$ & $\begin{array}{l}\text { Largura } \\
\text { de pós } \\
\text { praia } \\
(\mathrm{m})\end{array}$ & $\begin{array}{l}\text { Balanço } \\
\text { Potencial }\end{array}$ & $\begin{array}{c}\text { I.V. } \\
\text { Interanual }\end{array}$ & $\begin{array}{c}\text { I.V. } \\
\text { interdecadal }\end{array}$ & $\begin{array}{l}\text { I.V. } \\
\text { Geral }\end{array}$ \\
\hline 1 & 2.965 & -1.135 & 0.483 & 1.663 & 2.85 & -0.302 & 2.093 & 2.0 & 17.36 & 5.0 & 7.6 & 6.28 & 5.67 \\
\hline 2 & 0.560 & -1.305 & 0.488 & 1.682 & 1.54 & 0.044 & 2.107 & 4.0 & 45.30 & 5.0 & 6.52 & 7.11 & 5.67 \\
\hline 3 & -0.033 & -0.919 & 0.433 & 1.733 & 2.60 & -0.069 & 2.051 & 3.7 & 26.32 & 5.0 & 6.06 & 5.67 & 4.47 \\
\hline 4 & -1.208 & -1.008 & 0.486 & 1.858 & 7.90 & 0.056 & 1.977 & 3.0 & 19.44 & 6.5 & 7.87 & 6.08 & 5.12 \\
\hline 5 & -1.461 & -1.415 & 0.452 & 1.844 & 9.02 & 0.146 & 0.644 & 6.5 & 11.05 & 6.5 & 8.35 & 7.07 & 6.08 \\
\hline 6 & -1.025 & -1.225 & 0.182 & 2.020 & 4.48 & -0.302 & 1.469 & 4.0 & 11.92 & 3.8 & 5.91 & 6.16 & 5.2 \\
\hline 7 & -3.449 & -1.091 & 0.457 & 2.237 & 3.90 & -0.360 & 0.731 & 3.0 & 12.34 & 3.8 & 7.1 & 5.78 & 5.5 \\
\hline 8 & -2.151 & -1.201 & 0.470 & 2.798 & 4.69 & -0.010 & 1.405 & 5.3 & 16.67 & 5.3 & 7.65 & 6.57 & 5.75 \\
\hline 9 & 0.043 & -0.818 & 0.208 & 2.660 & 3.11 & -0.010 & 0.720 & 5.5 & 17.42 & 4.9 & 5.94 & 4.95 & 4.02 \\
\hline 10 & -0.281 & -0.548 & 0.289 & 1.469 & 2.68 & -0.154 & 1.993 & 4.0 & 17.02 & 2.6 & 4.4 & 4.14 & 3.4 \\
\hline 11 & 1.211 & -0.196 & 0.147 & 0.945 & 2.10 & 0.071 & 2.086 & 3.0 & 16.32 & 1.9 & 3.76 & 2.6 & 2.39 \\
\hline 12 & -8.260 & -1.126 & 0.733 & 0.541 & 3.20 & 0.153 & 1.977 & 3.0 & 20.47 & 6.5 & 10 & 6.13 & 6.8 \\
\hline 13 & -0.171 & 0.062 & 0.895 & 0.532 & 2.11 & 0.205 & 2.146 & 3.5 & 27.38 & 8.5 & 8.72 & 3.73 & 3.07 \\
\hline 14 & -1.294 & 0.029 & 0.850 & 0.544 & 2.02 & 0.332 & 1.861 & 4.0 & 34.78 & 5.8 & 7.64 & 3.53 & 3.23 \\
\hline 15 & -1.408 & -0.018 & 1.181 & 0.554 & 0.84 & -0.030 & 2.107 & 4.0 & 41.71 & 3.8 & 6 & 3.43 & 3.05 \\
\hline 16 & -1.163 & -0.293 & 1.195 & 0.468 & 2.63 & 0.065 & 2.093 & 2.0 & 22.72 & 6.5 & 7.4 & 3.99 & 3.4 \\
\hline 17 & -3.792 & 0.189 & 0.370 & 0.617 & 1.65 & 0.096 & 2.100 & 3.0 & 17.68 & 3.4 & 6.13 & 2.83 & 3.18 \\
\hline 18 & -3.637 & 0.028 & 0.435 & 0.821 & 2.11 & 0.382 & 2.072 & 3.0 & 22.50 & 2.6 & 6.24 & 2.86 & 3.27 \\
\hline 19 & -2.904 & -0.122 & 0.573 & 0.888 & 5.24 & 0.308 & 2.009 & 5.0 & 16.68 & 5.8 & 8.53 & 3.66 & 3.78 \\
\hline 20 & 1.078 & 0.187 & 0.672 & 0.726 & 2.38 & 0.000 & 1.439 & 6.0 & 20.09 & 3.7 & 5.4 & 3.06 & 2.77 \\
\hline 21 & 0.537 & -0.077 & 0.707 & 0.741 & 2.16 & 0.046 & 0.000 & 5.0 & 20.63 & 3.7 & 4.89 & 2.42 & 2.16 \\
\hline 22 & 0.726 & -0.343 & 0.694 & 0.764 & 4.34 & 0.046 & 1.977 & 3.0 & 15.01 & 7.0 & 7.44 & 3.82 & 3.23 \\
\hline 23 & 4.351 & -0.507 & 0.566 & 0.939 & 2.72 & 0.072 & 2.009 & 5.0 & 24.11 & 3.8 & 7.3 & 4.32 & 4.5 \\
\hline 24 & 2.896 & -1.058 & 0.659 & 1.928 & 3.57 & -0.432 & 2.283 & 2.0 & 24.90 & 3.7 & 7.32 & 6.62 & 5.95 \\
\hline 25 & 4.021 & -0.521 & 0.934 & 1.401 & 2.17 & 0.197 & 1.861 & 4.0 & 33.50 & 8.5 & 10 & 5.34 & 5.25 \\
\hline 26 & -3.277 & -0.386 & 0.761 & 1.094 & 1.98 & -0.424 & 2.100 & 3.0 & 28.82 & 1.0 & 5.38 & 4.26 & 4.24 \\
\hline
\end{tabular}

corrente longitudinal (Residual Drift), conforme Carter (1988).

BALANÇO SEDIMENTAR POTÊNCIAL (BSP) A partir da classificação dos limites das células em divergentes, pulsantes e convergentes, (Mazzer 2007), foi efetuada uma classificação das células costeiras quanto ao seu balanço potencial de sedimentos. Para fins de caracterização da natureza dos limites das células costeiras em relação à erosão costeira os limites foram atribuídos de valores de 10 (convergentes), 5 (pulsantes) e 1 (divergentes). Foram considerados os diferentes limites nas três ondulações, sendo o valor final obtido por média ponderada pela freqüência relativa de ocorrência destas (Tab. 1).

LARGURA MÉDIA DA PÓS-PRAIA(LPP), INCLINAÇÃO MÉDIA DO ESTIRÂNCIO (IME) E GRANULOMETRIA MÉDIA NO ESTIRÂNCIO (TMG) Foram realizados 40 perfis praiais com coletas de sedimentos no estirâncio e medidas de sua inclinação e da largura da praia, no período entre janeiro e março de 2007 (Mazzer et al. submetido), posteriormente (até 7 dias) à incidência de eventos de ondulações de média a alta energia.

As medições dos parâmetros morfológicos em cada perfil foram efetuadas com o auxílio de trena e clinômetro (método descrito em Souza 1997, 2007), com 
distâncias entre cada perfil variando entre 100 a 300 m; as medidas de inclinação foram determinadas a partir da média de 4 a 6 tomadas em cada pefil.

A granulometria foi determinada em laboratório através do método do peneiramento a seco (descrito em Suguio 1973), sendo utilizada a média simples de cada amostra (Folk \& Ward 1957 apud Suguio 1973).

Análise da vulnerabilidade costeira $\mathrm{A}$ análise de vulnerabilidade da orla costeira foi realizada a partir de duas etapas: a discretização e normalização dos valores brutos das variáveis, e posterior construção de índices baseados nas taxas de variação da linha de costa (interanual e interdecadal).

NORMALIZAÇÃO DE VARIÁVEIS Os dados das variáveis foram normalizados pela transformação em coeficientes de freqüência relativa, de forma a apresentarem valores entre 0 e 10, possibilitando a aplicação juntamente com os índices de vulnerabilidade .

CONSTRUÇÃO DE ÍNDICES DE VULNERABILIDADE (I.V.) A fase inicial da construção dos índices de vulnerabilidade utilizou um teste preliminar de comparação entre médias de Shapiro \& Wilk afim de verificar a normalidade dos dados. Posteriormente, foi realizada a análise fatorial tipo "Q", a fim de verificar a relação entre as 10 variáveis supracitadas.

Os resultados demonstraram que as taxas de variação da linha de costa são responsáveis por cerca de $40 \%$ de toda variação, enquanto as demais variáveis mostraram pouca contribuição, levando-nos a considerar que essas taxas podem ser utilizadas como balizadores para a construção dos índices de vulnerabilidade. Sendo assim, para cada escala de variação da linha de costa foi gerado um índice de vulnerabilidade, a partir de agregação linear entre as duas taxas de variação da linha de costa (variável independente) e as oito variáveis (dependentes) restantes.

Os dados foram organizados de forma que a variação seqüencial dos valores de cada variável fosse comparada com a seqüência decrescente de taxas de variação da linha de costa em cada praia. Tal comparação verificou se havia validação com o suposto comporta- mento desta variáveis frente ao processo de erosão costeira, o qual ora denominamos de "regras de erosão".

$\mathrm{Na}$ figura 4, as setas indicam o comportamento das variáveis 3 a 8 , frente a o aumento de taxas de erosão representadas pelas variáveis 1 e 2 .

Tais regras estão baseadas na bibliografia pertinente, sendo alguns exemplos tomados para as variáveis (a numeração correspondente encontra-se na figura 4) que seguem: 1 e 2 Dolan et. al (1991) e Crowell et. al (1993); 3, 4, 6 e 10 - CERC (1984) e Carter (1988); 5- Brunn (1962); Bush et al. (1996) e Mazzer (2004); 7,8 e 9 Brunn (1952); Dubois (1982); Souza (1997) e Souza (1998), entre outros autores.

Para cada comparação entre taxa e valor de variável foi determinado o valor de 1 ou 0 para validação ou não-validação, respectivamente, transformando os dados num modelo de representação binomial. Deste modo, gerou-se um peso para cada variável em cada OM para todas as praias, resultado de seu coeficiente de correlação com as taxas de variação da linha de costa.

Posteriormente, os pesos das variáveis em cada praia foram somados e discretizados pela média ponderada (por número de ocorrência $-n$, que no caso é o número de célula costeira por praia), resultando num peso final para cada variável. Os pesos finais representam a contribuição de cada variável em relação às demais, para cada taxa de variação da linha de costa, as quais se mostraram de forma distinta, conforme mostram as equações 3 e 4 .

A partir desses dois índices foi gerado um índice geral (I.V.-Geral) contemplando ambas as escalas e variáveis (Equação 5).

$$
\begin{aligned}
& \text { I.V.-Anual }=0,4 * \text { taxa interanual }+[0,6 \\
& (0,12 \mathrm{HB})+(0,16 \mathrm{ANT})+(0,11 \mathrm{ALT})+ \\
& (0,14 \mathrm{CLR})+(0,08 \mathrm{TMG})+(0,17 \mathrm{IME}) \\
& +0,10 \mathrm{LPP})+(0,13 \mathrm{BSP})]
\end{aligned}
$$

$$
\begin{aligned}
& \text { I.V.- Interdecadal }=0,4 * \text { taxa interde- } \\
& \text { cadal }+[0,6 *(0,16 \mathrm{HB})+(0,16 \mathrm{ANT}) \\
& +(0,06 \mathrm{ALT})+(0,09 \mathrm{CLR})+ \\
& (0,13 \mathrm{TMG})+(0,12 \mathrm{IME})+0,14 \mathrm{LPP}) \\
& +(0,13 \mathrm{BSP})]
\end{aligned}
$$

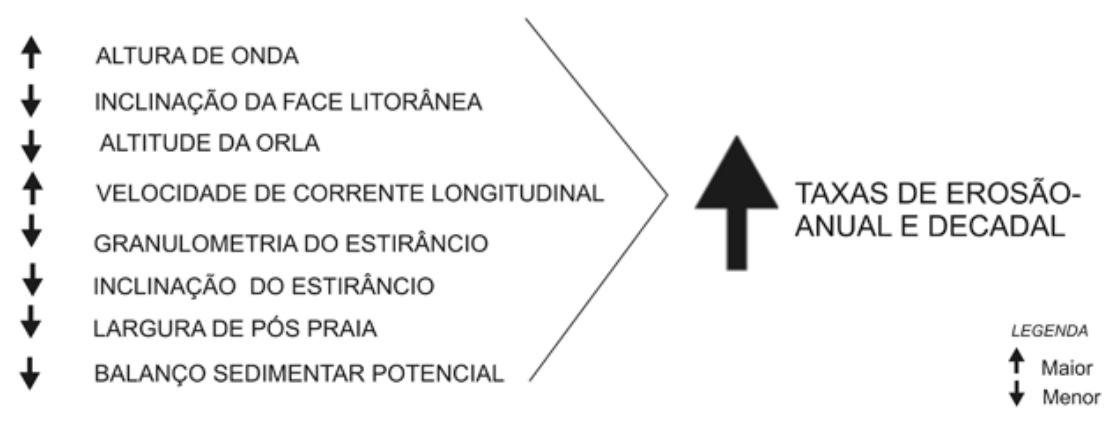

Figura 4 - Quadro de regras para tornar as variáveis como indicadores de erosão. 
I.V. - Geral $=0,2$ taxa interanual + 0,3 taxa interdecadal $[0,5(0,16 \mathrm{HB})+$ $(0,16 \mathrm{ANT})+(0,06 \mathrm{ALT})+(0,09 \mathrm{CLR})$ $+(0,13 \mathrm{TMG})+(0,12 \mathrm{IME})+0,14 \mathrm{LPP})$ $+(0,13 \mathrm{BSP})]$

Onde:

TXA é taxa de variação da linha de costa em escala interanual;

TXD é taxa de variação da linha de costa em escala interdecadal;

HB é a altura de onda na quebra;

IFL é inclinação da face litorânea (shoreface);

ALT é a altimetria da faixa de orla;

CLR é a velocidade residual de corrente longitudinal;

IME é a inclinação média do estirâncio;

TMG é a granulometria média no estirâncio;

LPP é a largura média do pós praia e

BSP é o balanço de sedimentos potencial.

As classes de vulnerabilidade obtidas foram agrupadas em quatro intervalos: 0-2 Muito Baixo; 2-3 Baixo; 3-6 Médio;6-8 Alto; 8-10 Muito Alto.

RESULTADOS E DISCUSSÕES A vulnerabilidade costeira entre as praias analisadas apresentou-se variável entre os três índices aplicados. A estimação das variáveis mostrou, em ambas as escalas de taxa de erosão (I.V.-Anual e I.V. Decadal), que as maiores correlações ocorreram com a inclinação da face litorânea, altura de onda e declividade da face praial, alcançando pesos superiores a $14 \%$ (Fig. 5).

As variáveis relacionadas com as células costeiras (velocidade da corrente longitudinal residual e balanço potencial de sedimentos), juntamente com a largura média da pós-praia, mostraram-se secundariamente mais importantes, com peso superior a $10 \%$.

Por outro lado, outras variáveis emergiram como mais importantes em cada índice. Em escala interanual, por exemplo, a velocidade residual da corrente longitudinal foi a segunda variável mais importante (Tab. 2), ao passo que nos demais índices a largura média da pós-praia se sobressaiu.

A variável que foi menos correlacionada com os índices testados foi a altimetria média da orla marítima, gerando pesos inferiores a 8\%, com exceção da escala interanual, onde alcançou 10\% (Fig. 5).

Na perspectiva geral, a linha de costa da área de estudo apresentou a maior ocorrência da classe "Alta". No índice IV-Anual, a classe "Alta" está presente em mais da metade da linha de costa, enquanto nas demais aparece em cerca de um terço (Fig. 6).

As classes "Média" e "Muito Baixa" também ocorrem de forma expressiva, com cerca de $20 \%$ cada, destacando-se ainda nesta última, a ocorrência de valores muito próximos nos três índices Tal fato denota locais de baixa energia, nos quais a maior parte das variáveis se apresentam com baixos valores, principalmente aquelas de maior peso.

Ainda que a menor freqüência das classes de vulnerabilidade tenha sido a "Muito Alta", esse trecho costeiro apresenta muita erosão, conforme constatado por Mazzer (2007) e Mazzer \& Dillenburg (submetido).

Índice de vulnerabilidade interanual (i.v. anual) As células costeiras que apresentaram grande energia de onda aliada à alta declividade de antepraia e taxa de erosão interanual pronunciada, localizadas no meio da praia da Armação e no extremo sul da Praia da Lagoinha do Leste, apresentaram vulnerabilidade Muito Alta, representadas por OM-23, OM-24 e OM-25 (Tab. 2).

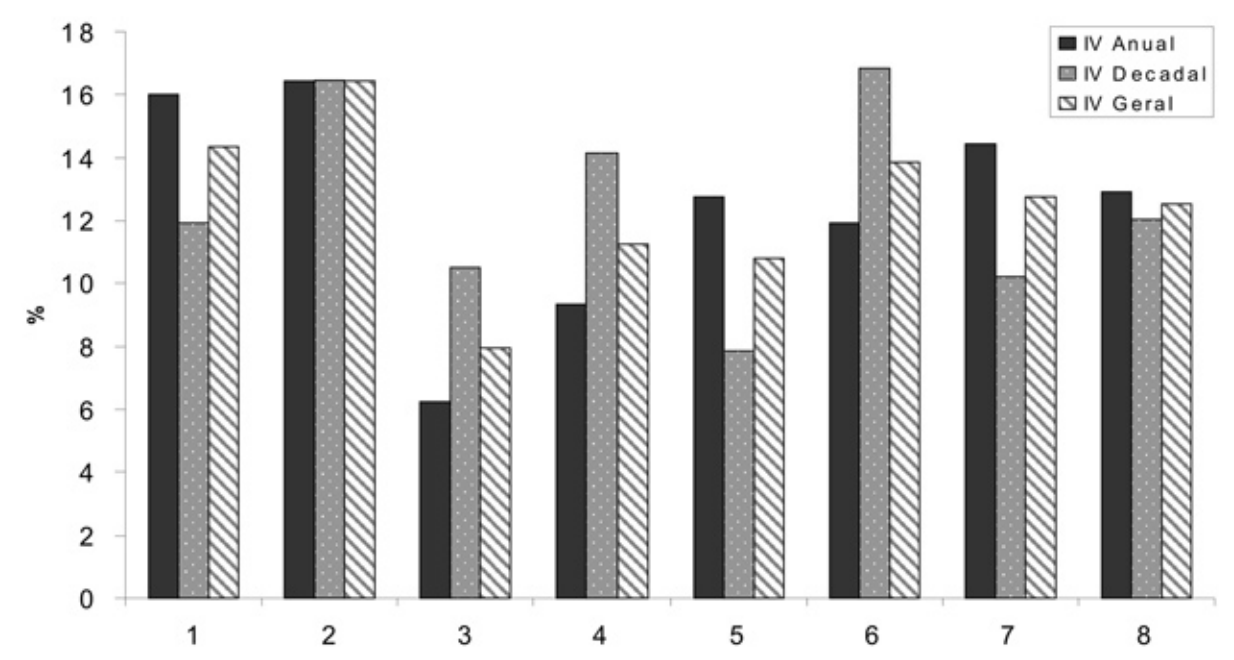

Figura 5 - Peso das variáveis (\%) encontrado para os três índices de vulnerabilidade. (1-Altura de onda na quebra; 2-Inclinação de face litorânea; 3-Altimetria média da orla; 4-Velocidade residual de corrente longitudinal; 5- Tamanho médio de grão no estirâncio;6- Declividade média no estirâncio; 7-Largura média de pós praia; 8-Balanço potencial de sedimentos. 


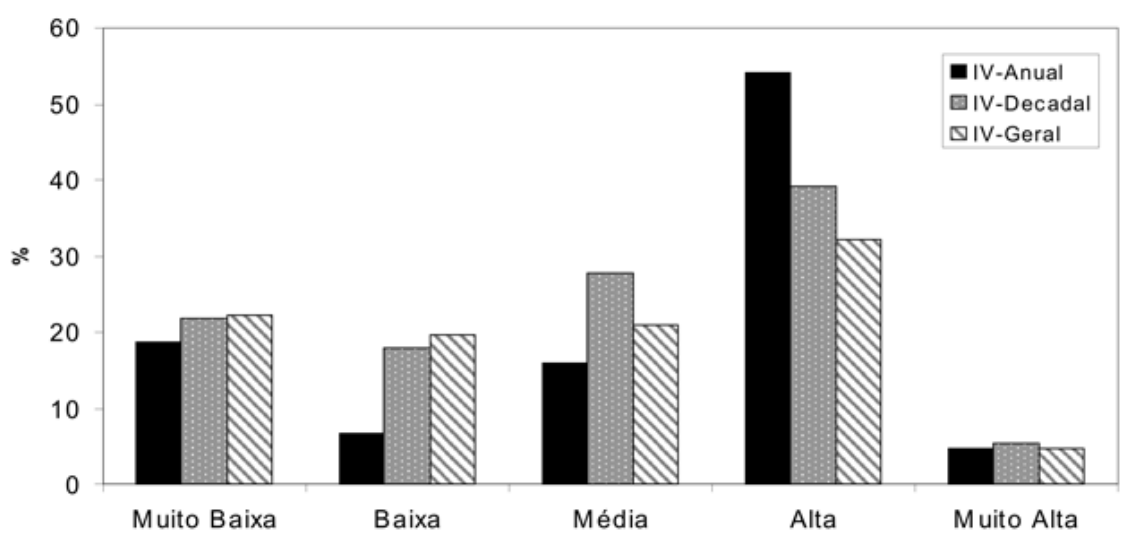

Figura 6 - Percentual de classes de vulnerabilidade na área de estudo.

Os locais de vulnerabilidade Alta ocorrem em todas as praias, predominando na maior parte dos arcos praiais mais extensos localizados nas praias da Armação e do Pântano do Sul-Açores. Em ambas essas praias ocorre ampla mobilização de sedimentos durantes eventos de alta energia de ondas, ocasionando erosão costeira, conforme constatado por Castilhos (1995), Mazzer (2004), Oliveira (2004), Simó \& Horn $\mathrm{F}^{\mathrm{o}}$ (2004) e Mazzer (2005), especialmente nos meios de praia (OM-7, OM-8, e OM- 24) (Figs. 3, 8 e 9), onde ocorre maior energia de onda e maiores taxas de erosão interanual (Mazzer \& Dillenburg, submetido). Ex- ceção é a localidade de Pântano do Sul (OM-11), que apesar de apresentar eventos de baixa energia, aparece com ampla variação da linha de costa positiva, provavelmente tendo a fonte de sedimentos proveniente de outras unidades de orla (OM-9, OM-10), uma vez que a intensa ocupação humana ocorre sobre as dunas frontais (Mazzer 2004).

Em praias menores, tais como as da Solidão Matadeiro e Lagoinha do Leste, as localidades com vulnerabilidade Alta ocorrem associadas aos promontórios rochosos nos extremos das mesmas (Figs. $7,8 \mathrm{e}$ 9; Tab. 2).
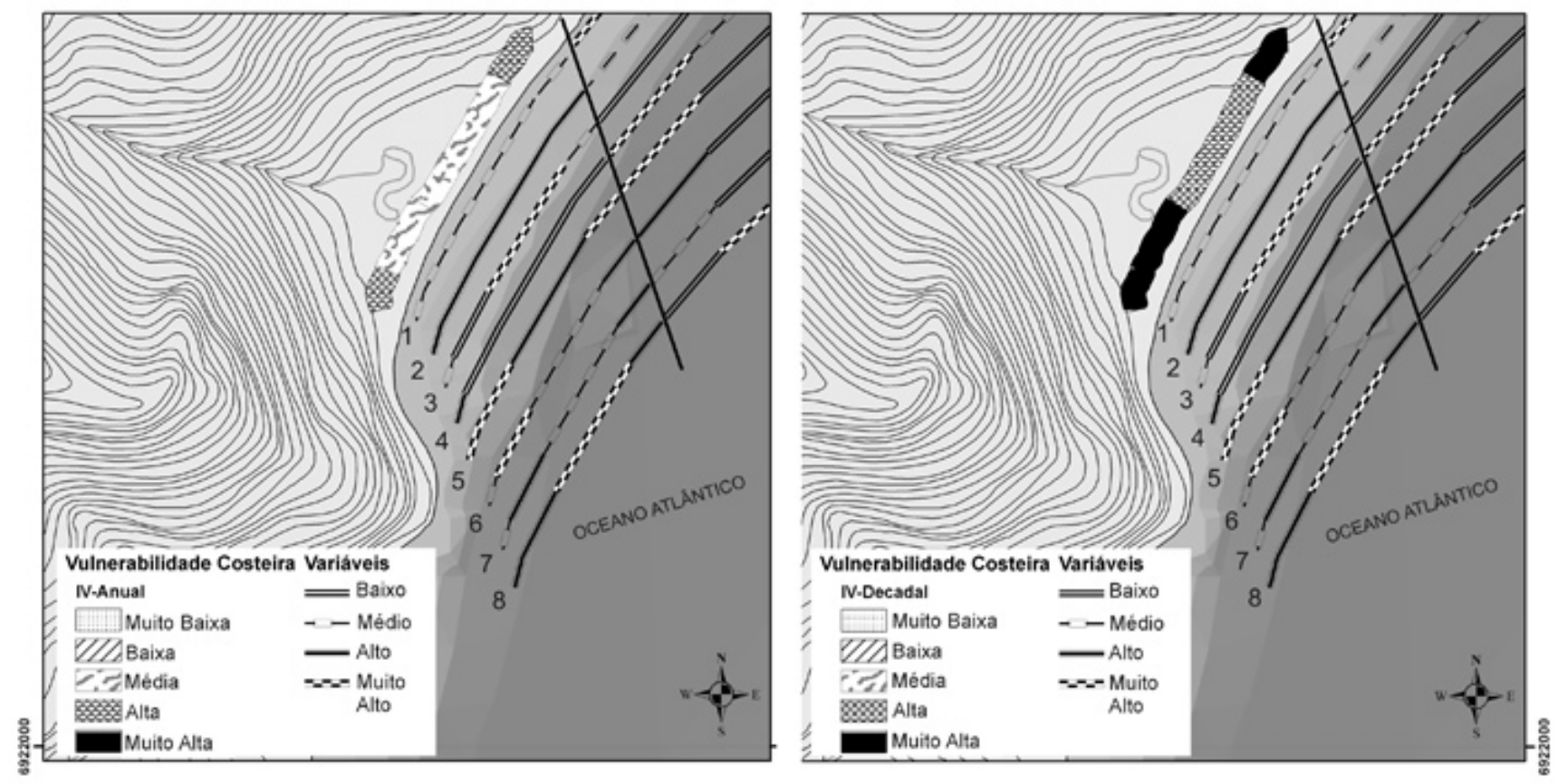

Figura 7 - Vulnerabilidade à erosão costeira na Praia da Solidão: (a) IV-Decadal; (b) IV-Anual. (traço preto oblíquo à linha de costa indica o limite norte com praia dos Açores)

1- Altura de onda na quebra; 2- Inclinação de face litorânea; 3- Altimetria média da orla; 4-Velocidade residual de corrente longitudinal; 5- Tamanho médio de grão no estirâncio;6- Declividade média no estirâncio; 7- Largura média de pós praia; 8-Balanço potencial de sedimentos. 

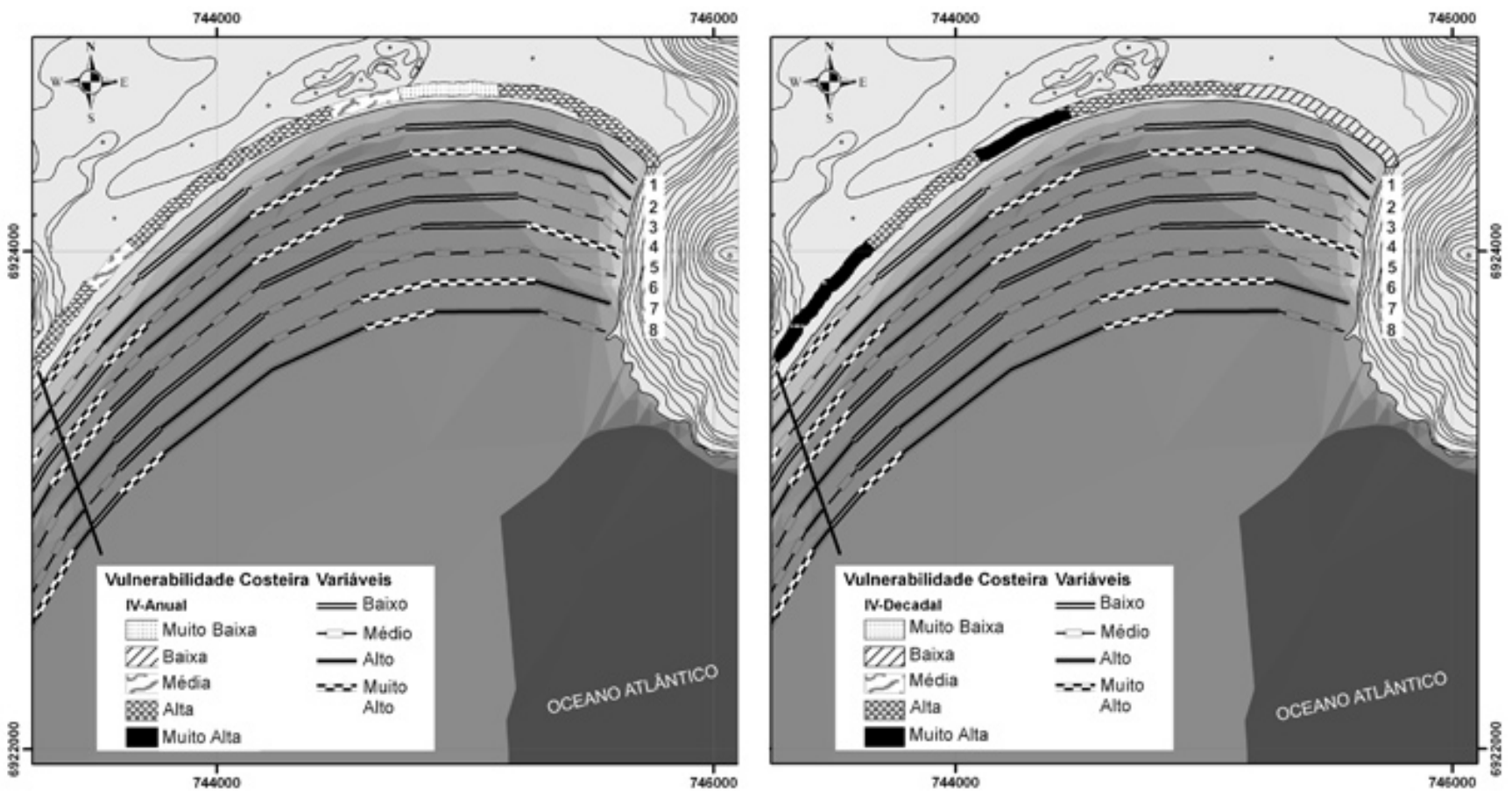

Figura 8 - Vulnerabilidade à erosão costeira na Praia do Pântano do Sul-Açores: (a) I.V.-Decadal; (b) I.V.Anual. 1- Altura de onda na quebra; 2 Inclinação de face litorânea; 3- Altimetria média da orla; 4- Velocidade residual de corrente longitudinal; 5- Tamanho médio de grão no estirâncio;6- Declividade média no estirâncio; 7- Largura média de pós praia; 8-Balanço potencial de Sedimentos.
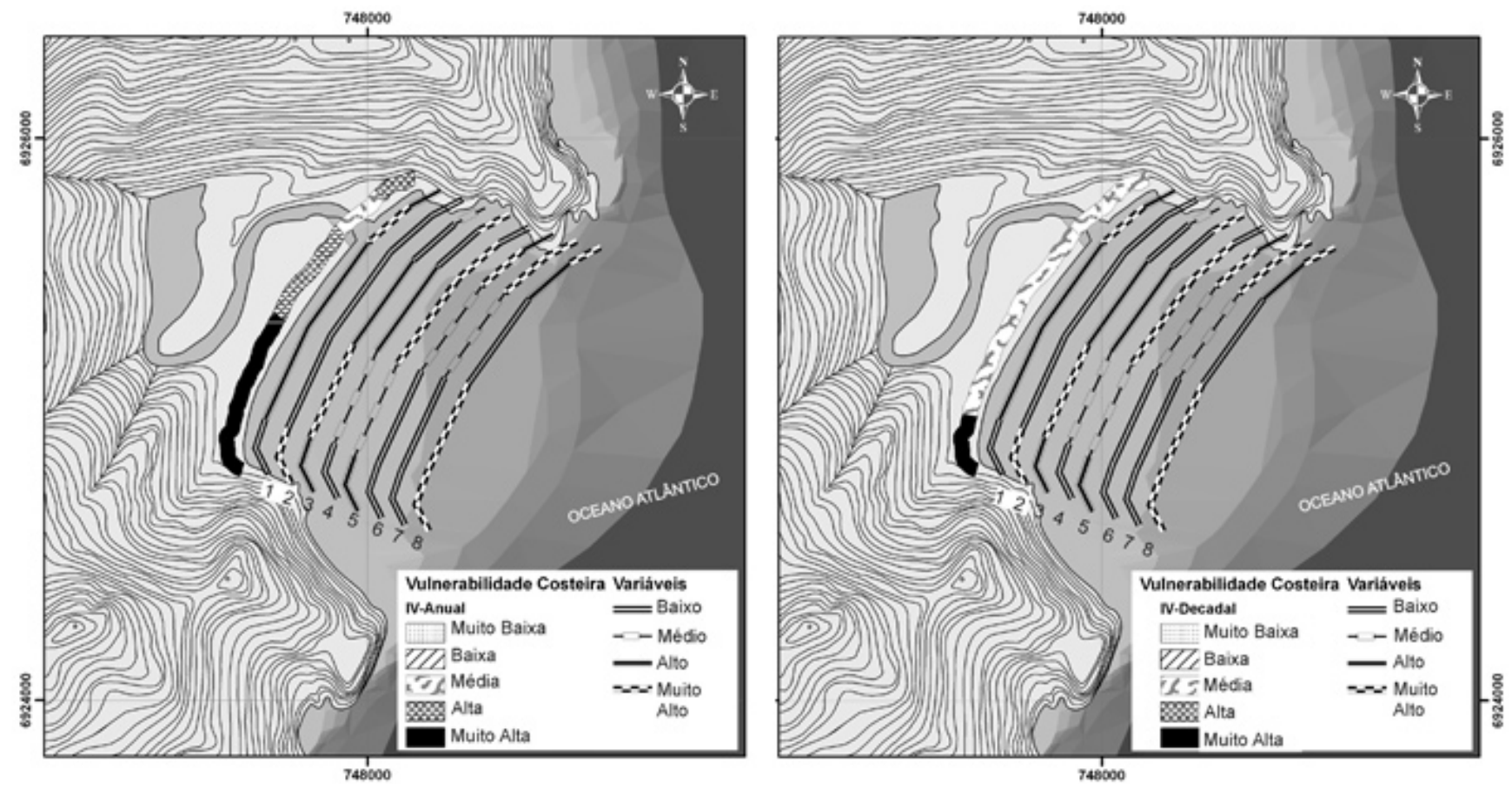

Figura 9 - Vulnerabilidade à erosão costeira na Praia da Lagoinha do Leste: (a) I.V.-Decadal; (b) I.V.-Anual. 1- Altura de onda na quebra; 2- Inclinação de face litorânea; 3- Altimetria média da orla; 4-Velocidade residual de corrente longitudinal; 5- Tamanho médio de grão no estirâncio;6- Declividade média no estirâncio; 7- Largura média de pós praia; 8-Balanço potencial de sedimentos.

As OM Moderadamente vulneráveis ocorrem no meio das praias menos extensas, a maior parte em locais com taxas de variação da linha de costa entre - 1,0 e $-0,5 \mathrm{~m} / \mathrm{ano}$, geralmente adjacentes às células costeiras com maior energia de onda e corrente longitudinal residual (Figs. 7, 10 e 11) (Tab. 2). 

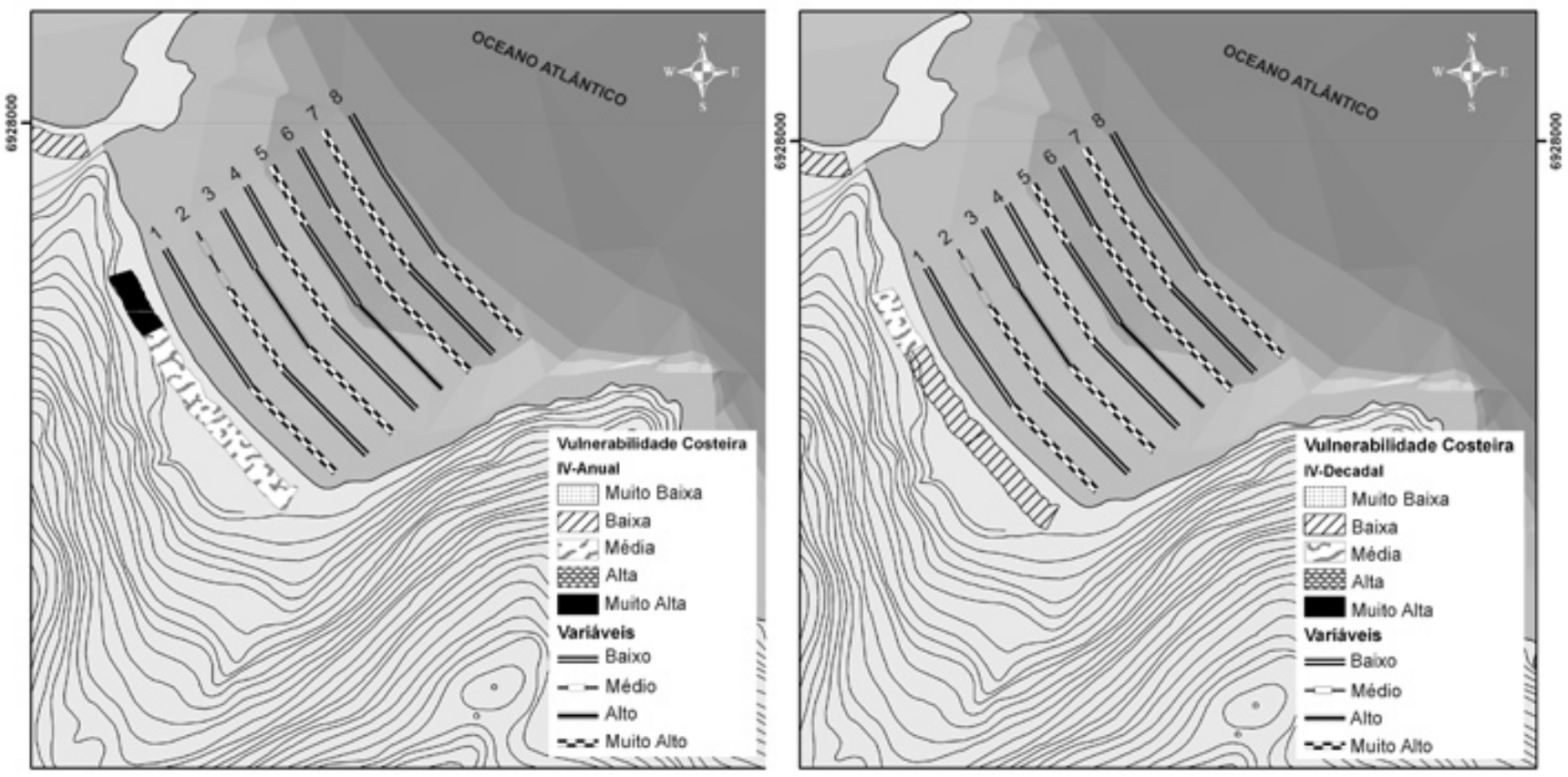

Figura 10 - Vulnerabilidade à erosão costeira na Praia do Matadeiro: (a) I.V.-Decadal; (b) I.V.-Anual. 1- Altura de onda na quebra; 2- Inclinação de face litorânea; 3- Altimetria média da orla; 4-Velocidade residual de corrente longitudinal; 5- Tamanho médio de grão no estirâncio; 6- Declividade média no estirâncio; 7Largura média de pós praia; 8- Balanço potencial de Sedimentos.
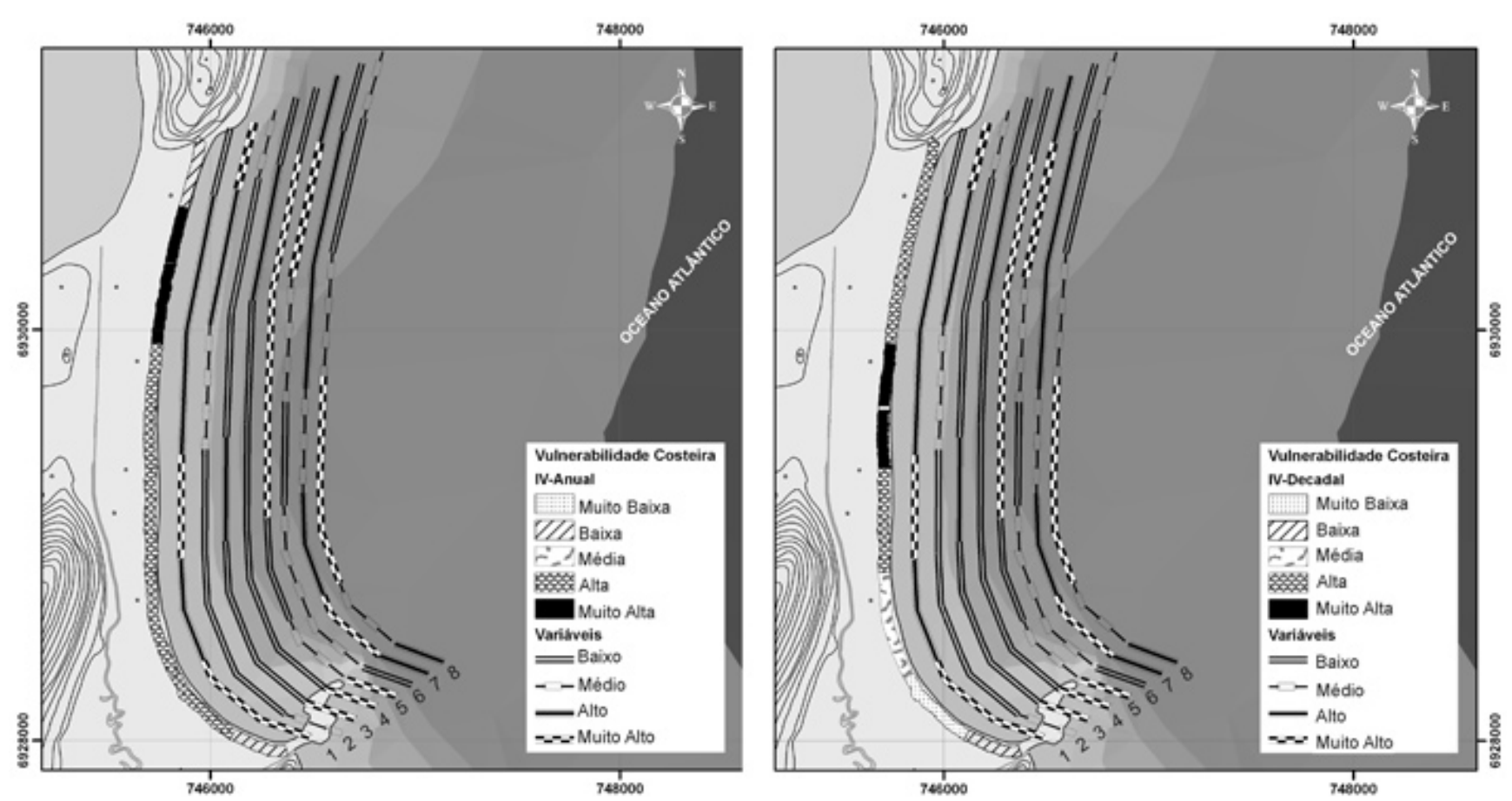

Figura 11 - Vulnerabilidade à erosão costeira na Praia da Armação: (a) I.V.-Decadal; (b) I.V.-Anual. 1- Altura de onda na quebra; 2- Inclinação de face litorânea; 3- Altimetria média da orla; 4-Velocidade residual de corrente longitudinal; 5- Tamanho médio de grão no estirâncio;6- Declividade média no estirâncio; 7- Largura média de pós praia; 8- Balanço potencial de Sedimentos.

A Praia do Matadeiro possui energia de onda de média a baixa (Mazzer et al., submetido) e vulnerabilidade Média na maior parte de sua extensão (Fig. 10), associada à alta instabilidade relativa à variação da linha de costa interanual (Mazzer \& Dillenburg, submetido). Locais com baixas taxas de erosão estão as- 
sociados às células costeiras de baixa energia, como a OM-20, no extremo sul da praia da Armação, e OM-11, na Praia de Pântano do Sul, ou a uma declividade de face praial elevada, associada ao tamanho de grão de areia que varia de grossa a cascalho (OM-11), apresentaram baixa vulnerabilidade.

Índice de vulnerabilidade interdecadal (i.v.-decadal) Neste índice, a largura média da pós-praia constituiu um bom indicador de vulnerabilidade à erosão costeira em escala interdecadal, juntamente com a altura de onda e a inclinação média da face litorânea.

A maior parte dos locais com vulnerabilidade Muito Alta ocorre no embaíamento Pântano do SulSolidão (Figs. 7 e 8). Nos extremos da Praia da Solidão e locais no meio da Praia dos Açores ocorrem as maiores taxas de erosão interdecadal (Mazzer \& Dillenburg, submetido), combinadas com as maiores alturas de onda nesse embaíamento.

Em outras partes da área de estudo, as unidades OM-7 OM-12 e OM 23 se apresentam muito vulneráveis, assim como ocorre no índice interanual (Figs. 8, 9 e 11).

Os trechos com vulnerabilidade Alta, também ocorrem na maior parte do embaíamento Pântano do Sul-Solidão e no trecho mais exposto às ondas da Praia da Armação, de forma alternada aos pontos de classe "Muito Alta".

A Praia da Lagoinha do Leste apresentou vulnerabilidade média em quase toda sua extensão, com exceção do extremo sul. As variáveis nessa praia apresentaram uma relação equilibrada entre a altura de onda elevada e baixas taxas de variação da linha de costa.(Fig. 9).

As classes Baixa e Muito Baixa de vulnerabilidade localizam-se em unidades com baixa energia de ondas e locais com baixas taxas de variação da linha de costa (Tab. 2), no extremo leste da Praia do Pântano do Sul, no centro e sul da Praia do Matadeiro, e ao sul da Praia da Armação (Figs. 8,10 e 11).

Índice de vulnerabilidade geral O Índice de Vulnerabilidade Geral apresenta resultados bastante semelhantes ao I.V.-Decadal, no qual as modificações representam a ponderação deste pelo I.V.-Anual. Como resultado, ocorreu a diminuição da vulnerabilidade nas unidades OM-23 e OM-18 nas praias da Armação e Matadeiro, respectivamente, e a diminuição quase generalizada na Praia da Lagoinha do Leste.

DISCUSSÕES No contexto do presente trabalho esta variável foi utilizada como fator independente, assumindo que a mesma estabelece a referência de estabilidade/instabilidade da linha de costa., e, portanto, de erosão costeira. No entanto, sua análise foi efetuada sob duas perspectivas temporais, interanual e interdecadal, de forma a gerar subsídios ao gerenciamento costeiro (Mazzer \& Dillenburg, submetido).

Devido ao fato das variáveis terem seus indicadores provenientes tanto de processos modelados como de resultados de processos medidos, a decli- vidade da antepraia mostrou-se associada a ambas as escalas. Conforme Hanson et al. (2003), a antepraia tem, de forma geral, sua atividade pautada na escala decadal, ocorrendo nesta escala, um tempo de evolução mais profundo que estaria associado com o balanço sedimentar que envolve fontes e/ou sumidouros de areia, no sentido longitudinal à linha de costa.

A altura média de onda teve grande importância na análise de vulnerabilidade costeira, estando amplamente correlacionada com a declividade da antepraia e com as taxas de erosão em ambas as escalas. Sugerese que tal fato indique a qualidade dessa variável em expressar outros atributos, como orientação de costa e grau de exposição, utilizados de forma consolidada em outros trabalhos (Gornitz et al.1992, Dal Cin \& Simeoni 1994, Menezes \& Klein 2004). Dessa forma, essa variável reflete a energia média, no caso, por unidade de orla marítima definida pelas células costeiras.

Contudo, as variáveis relacionadas às células costeiras (balanço sedimentar potencial e velocidade residual de correntes longitudinais), também assumiram grande importância na análise, revelando serem sensíveis à erosão costeira, confirmando as relações entre o balanço sedimentar e a variação da linha de costa, conforme Carter (1988), Inman (2003) e Mazzer (2007).

Ademais, a utilização do conceito de células costeiras na espacialização, representada pelos limites entre as células costeiras que seccionam a orla marítima em unidades homogêneas, reforça a perspectiva no balanço sedimentar, uma vez que, a morfodinâmica da linha de costa, se dá entre outros fatores, através ocorrência de ajustes topográficos, e transferência de sedimentos de forma perpendicular e longitudinal à linha de costa (Cowell et al. 1997).

Por outro lado, muitos dos trabalhos sobre vulnerabilidade e risco costeiro apresentam abordagens distintas na espacialização, incluindo o gradeamento (Gornitz et al. 1992), a fisiografia costeira (Dal Cin \& Simeoni 1994, Bush et al. 1996, Mazzer 2004) ou ainda abrangendo toda a planície costeira (Gallerini et al. 2003, Hennecke \& Cowell 2000). Tal diferença fundamenta-se na busca da presente abordagem na aproximação entre conceitos de espacialização em unidades homogêneas (comuns e de fácil aplicação em gerenciamento costeiro), e processos costeiros, especificamente balanço sedimentar.

Porém, Thumerer et al. (2000) e Gallerini et al. (2003) já haviam utilizado o conceito de unidades ambientais homogêneas para cálculo de risco de elevação do nível do mar na Inglaterra e Itália, respectivamente, destacando a vantagem para fins de gerenciamento costeiro e de riscos, assim como permitirem serem objetos de modelagem matemática e predições de cenários.

A área de estudo (com exceção da praia da Lagoinha do Leste), já havia sido compartimentada por Mazzer (2004) em 34 trechos baseado no gradiente de altura de onda e nível de ocupação costeira. Similarmente, tal estudo teve fins de análise da vulnerabilidade costeira, porém, utilizando o método dos geoindicadores (Bush et al, 1996) (Cobum 2001), o qual incorpora 
alguns fatores antrópicos na análise.

Por outro lado, outras áreas consideradas de baixa vulnerabilidade por Mazzer (2004) e Simó \& Horn F ${ }^{\circ}$ (2004), como a porção central e norte da praia da Armação e extremo sul da praia da Solidão, foram classificadas como de vulnerabilidade alta no presente trabalho.

A maior facilidade de ocupação ocorre em áreas mais protegidas do sul da ilha, ocasionando problemas de erosão crônica (Cruz 1999), geralmente devido ao aprisionamento dos sedimentos dispostos nas dunas frontais De forma similar, Perillo et al. (1999) associa as áreas com maior erosão na costa da Argentina, àquelas sem a presença de dunas frontais e com maior presença antrópica.

A classificação da costa em níveis de vulnerabilidade e risco permite o estabelecimento de diretrizes de uso e ocupação destes trechos, porém, para fins de gerenciamento costeiro, a definição clara de limites e critérios se faz necessária para torná-la útil (Cooper \& Mc Laughin 1998).

A determinação de níveis de erosão a partir das unidades de orla marítima delimitadas pelas células costeiras inclui certas implicações que devem ser consideradas, tais como: i) a homogeneização dos segmentos de linha de costa, atenua os efeitos pontuais da erosão distribuindo e fundindo sua informação com as demais incluídas nos limites da célula; ii) Em praias onde a variabilidade da estrutura costeira é mais complexa, o uso das células pode gerar uma difícil delimitação e ser passível de erro para aplicações de análise de vulnerabilidade.

Por outro lado, as determinações de unidades homogêneas, a partir de células costeiras, contemplam em sua concepção um ciclo sedimentar, o que se relaciona diretamente com o equilíbrio da linha de costa (Carter 1988), sobretudo em intervenções como dragagens e instalação de estruturas de apoio náutico (Griggs et al.1987), e para efeitos de abordagem integradora de escalas temporais (Cowell et al. 2003).

As ações e objetivos de gerenciamento costeiro ocorrem em diversas escalas (Carter 1988), e frente a isso, as análises e classificações costeiras devem identificar as escalas de processos e respostas da linha de costa, de forma a subsidiar estas ações.

CONCLUSÕES A integração de diferentes metodologias no desenvolvimento da presente proposta foi possibilitada pelo uso do Sistema de Informação Geográfica, que como ferramenta, permitiu tratar e operar dados de natureza diversa sob um arcabouço espacial vinculado ao balanço sedimentar costeiro.

Ademais, o modelo metodológico proposto pode (e deverá) ser melhorado através da alimentação com mais dados coletados em campo, e de séries temporais mais longas, incluindo aí: volume sedimentar de pós praia, volume sedimentar transportado por correntes longitudinais, entre outros; o que permitirá reajustar as relações entre variáveis, validar os resultados, além de ser aplicado à outras praias arenosas.

Por outro lado, tem atuação limitada em problemas associados com processos costeiros de alta freqüência e de localização pontual, uma vez que está fundamentado no conceito de espacialização das células costeiras como unidades relativamente homogêneas.

Neste contexto, as implicações do presente trabalho visam possíveis aplicações em ações de gerenciamento costeiro, uma vez que a criação de unidades permitiu atar objetos espaciais definidos (OMs), distintas escalas temporais de erosão e perspectiva sistêmica relativa ao balanço sedimentar costeiro, as quais podem apoiar diretrizes distintas de uso e ocupação na orla marítima.

A análise vulnerabilidade da orla marítima à erosão costeira e a elevação do nível do mar poderia constituir em elemento constante na realização de planos diretores, zoneamento ecológico econômico costeiro, e outros instrumentos de planejamento. Desta forma, preencheria uma lacuna em relação à análise geotécnica na zona litorânea, agindo no sentido de evitar ou atenuar perdas e danos, em geral.

\section{Referências}

Araújo C.E.S., Franco D., Melo E., Pimenta F. 2003. Wave Regime Characteristics of the Southern Brazilian Coast. In: Copedec, International Conference On Coastal and Port Engineering in Developing Countries, 6, Colombo, Sri Lanka, Sri Lanka,, Proceedings, p. 1-15.

Bird E. 1985. Coastline Changes. New York, John Wiley and Sons, $219 \mathrm{p}$.

Bigarella J.J., Becker R.D., Santos G.F. 1994. Estrutura e origem das paisagens tropicais e subtropicais. Editora da UFSC, Florianópolis, 429 p.

Brasil. 2004. Decreto $n^{\circ} 5.300$ de 08 de dezembro de 2004.

Bray M.J., Carter D.J., Hooke J.M. 1995. Littoral Cell Definition and Budgets for Central Southern England. Journal of Coastal Research 11(2):38-400.

Brunn P. 1962. Sea level rise as a cause of shoreline erosion.
Journal of Waterways and Harbor 88:117-130.

Bush D.M., Pilkey Jr. O.H., Neal W.J. 1996. Living by the rules of the sea. London, Duke University Press, 179 p.

Camfield F.E. \& Morang A. 1996. Defining and Interpreting Shoreline Change. Ocean and Coastal Management 32(3):129-151.

Capobianco M., De Vriend H.J., Nicholls R.J., Stive M.J.F. 2001. Coastal Area Impact and Vulnerability Assesment: The Point of View of a Morphodinamic Modeller. Journal of Coastal Research, 15:701-716.

Carter R.G.W. 1988. Coastal Environments: An Introduction of Physical, Ecological and Cultural Systems. London, Academic press, 617p.

Caruso Jr. F. 1993. Mapa Geológico da Ilha de Santa Catarina - Texto explicativo e mapa- escala 1:100.000. Notas Técnicas, 6:1-28. 
Castilhos J.A. 1995. Estudo Evolutivo, Sedimentológico e Morfodinâmico da Planície Costeira e Praia da Armação - Ilha de Santa Catarina, SC. Dissertação de Mestrado. Departamento de Geociências, Universidade Federal de Santa Catarina, $134 \mathrm{p}$.

Clark J.R. 1995. Coastal Zone Management Handbook. Boca Raton Florida, CRC Press, 720 p.

COASTAL ENGINEERING RESEARCH CENTER (CERC). 1992. Using morphology to determine net littoral drift directions in complex systems. Coastal Engineering Technical Note, 30:1-8.

COASTAL ENGINEERING RESEARCH CENTER (CERC). 1984. Manual of Coastal Engineering. Florida, US. Army Corps of Engineering, Vol.1, 598 p.

Cobum A.S. 2001. Reducing Vulnerability of North Carolina Communities: A Model Approach for Identifying, Mapping and Mitigating Coastal Hazards. Program for the Study of Developed Shorelines, Duke University. Disponível em: http://www.env.duke.edu/psds/docs.htm. Acessado em 5 de outubro de 2003.

Cooper J.A.G. \& Mc Laughin S. 1998. Comtemporary Multidisciplinary Approaches to Coastal Classification and Environmental Risks Analysis. Journal of Coastal Research, 2(14):512-524.

Cowell P.J., Stive M.J.F., Niedoroda A.W., De vriend H.J., Swift D.J.P., Kaminsky F., Capobianco M. 2003. The Coastal Tract (Part 1): A Conceptual Approach Aggregated Modeling of Low order Coastal Change. Journal of Coastal Research, 4(19):812-827.

Cowell P.J. \& Thom B.G. 1997. Morphodynamics of Coastal Evolution. In: Carter R.W.W. \& Woodroffe C.D. (eds.) Coastal evolution: late quaternary shoreline morphodynamics. Cambridge, University Press, 539 p.

Crowell M., Leatherman S.P., Buckley M.K. 1993. Shoreline Change Rate Analysis: Long Term versus Short Term Data. Shore and Beach, 61:13-20.

Cruz O. 1999. A Ilha de Santa Catarina e o continente próximo: um estudo de geomorfologia costeira. Florianópolis, Editora da UFSC, 276p.

Dal Cin, R. \& Simeoni U. 1994. A model for determinining the Classification, Vulnerability and Risk in the Southern Coastal Zone of the Marche (Italy). Journal of Coastal Research, 10(1):19-29.

Dillenburg S., Esteves L.S., Tomazelli L. 2004. A critical evaluation of coastal erosion in Rio Grande do Sul, Southern Brazil. An. Acad. Bras. Ciênc. 76(3):611-623. Disponível em http://www.scielo.br/pdf/aabc/v76n3/ a14v76n3.pdf. Acesso em 25 de novembro de 2005.

Dolan R., Fenster M.S., Holme S.J. 1991. Temporal Analysis of Shoreline Recession and Acretion. Journal of Coastal Research, 7:723-744.

Dubois R.N. 1982. Relation among Wave Conditions, Sediment Texture, and Rising Sea Level: an Opinion. Shore and Beach, 4:30-32.

Gallerini G., De Donatis M., Devoti S., Gabellini M., Nisi M.F., Silenzi S. 2003. An Integrated Gis Method To Evaluate Susceptibility And Hazard Of Sea Level Rise In Coastal Plains: The Versilia Plain. In: CoastGis'03, Int. Symp. on GIS and Computer Cartography for Coastal Zone Management, Proceedings. Disponível em: http:// www.gisig.it/coastgis. Acessado em 23 de Junho de 2004.

Gornitz V.M. Daniels R.C., White T.W., Birdwell K.R. 1992. The Development of a Coastal Risk Assesment Database: Vulnerability to Sea Level Rise in the U.S. Southeast. Journal of Coastal Research SI, 12:327-338.

Gré J.C.R., Castilho J.A, Horn Filho N.O. 1997. Quaternary Deposits of the Pântano do Sul Beach, Santa Catarina Island, Brazil. In: Colóquio Franco-Brasileiro de Manejo Costeiro de Ilha de Santa Catarina, Atas, p. 211-218.

Griggs J.B. 1987. Littoral cells and harbor dredging along the Califórnia coast. Environmental Geology, 10:7-20.

Hanson H., Aarkinkhof S., Capobianco M., Jimenez J.A., Larson M., Nicholls R.J., Plant N.G., Southgate H.N., Steetzel H.J., Stive M.J.F., De Vriend H.J. 2003. Modelling Coastal Evolution on Yearly to Decadal Time Scales. Journal of Coastal Research, 4(19):812-827.

Hennecke W.G. \& Cowell P. 2000. GIS Modeling of Impacts of an Accelerated Rate of Sea Level on Coastal Inlets and Deeply Embayed Shorelines. Environmental Geosciencies, 7:137-148.

Hogben N., Dacunha N.M.C \& Oliver G.F. 1986. Global Wave Statistics. New York, Chapman and Hall, 661 p.

Hughes P., Brundrit G.B., Searson S. 1992. The Vulnerabilityof Walvis Bay to Rising Sea Levels. Journal of Coastal Research, 8:868-881.

Inman D.L. 2003. Littoral Cells. In: Schwartz M. (ed.) Encyclopedia of Coastal Science. The Earth Science Encyclopedia On Line, p. 1-20. Disponível em: http://repositories.cdlib.org/cgi/viewcontent.cgi? article $=1037 \&$ context $=$ sio. Acessado em 08/12/2006.

INTERNATIONAL PANEL OF CLIMATE CHANGE (IPCC). 2007. Fourth Assessment Report Climate Change: Observations: Oceanic Climate Change and Sea Level. United Nations Environment Program-UNEP. Disponível em: http://www.ipcc.ch. Acesso em 20/ 06/2007.

INSTITUTO DE PLANEJAMENTO URBANO DE FLORIANÓPOLIS-SC (IPUF). 2002. Levantamento Aerofotogramétrico da Ilha de Santa Catarina. Ortofotocartas. Escala 1:2.000. Florianópolis.

INSTITUTO DE PLANEJAMENTO URBANO DE FLORIANÓPOLIS-SC (IPUF). 1979. Levantamento Aerofotogramétrico-Aglomerado Urbano de Florianópolis. Escala: 1.10.000. Folha SG. 22-Z-D-1-SO-C, Florianópolis, Mapa Topográfico.

Klein R. \& Nicholls R. 1999. Assessment of Coastal Vulnerability to Climate Change. Ambio, 28:182-187.

Mazzer A.M. (2007). Proposta Metodológica de Análise de Vulnerabilidade da Orla Marítima à Erosão Costeira: Aplicação na Costa Sudeste da Ilha de Santa Catarina, Florianópolis-SC, Brasil. Tese de Doutoramento em Geociências. Programa de Pós Graduação em Geociências, Universidade Federal do Rio Grande do Sul, 169p.

Mazzer A.M. 2005. Aplicação de Taxas de Variação da Linha de Costa na Praia da Armação. In: Cong. de Assoc. Brasileira de Estudos do Quaternário, 10, Guarapari, Espirito Santo, Anais, CD-Rom. 
Mazzer A M. 2004. Analise da Vulnerabilidade Costeira com uso de Sistema de Informação Geográfica: Uma aplicação ao trecho litorâneo sul da Ilha de Santa Catarina.. In: Simpósio Nacional de Geomorfologia, 5, Santa Maria, Anais, CD-Rom.

Mazzer A.M. \& Dillenburg S.R. (submetido) Variações Temporais da Linha de Costa em Praias Arenosas Dominadas por Ondas do Sudeste da Ilha de Santa Catarina (Florianópolis-SC) Pesquisas em Geociências.

Mazzer A.M., Souza C.R., Dillenburg S.R., Bacilla C. (submetido). Determination of Coastal Cells at Southeast of Santa Catarina Island. Geomorphology.

Menezes J.T. \& Klein A.H. 2004. Coastal Erosion Vulnerability Analysis Methodology. In: Int. Coastal Symp., $8^{\text {th }}$, Proceedings, p.196-199.

MINISTÉRIO DO MEIO AMBIENTE (MMA). 2006. Projeto Orla: Subsidios para um Projeto de Gestão. Brasília, MMA, $101 \mathrm{p}$.

Miott G. 2002. Efeito do Estado de Equilíbrio em Planta na Sedimentologia de Praias desenvolvidas entre Promontórios. Dissertação de Mestrado. Programa de Pós Graduação em Geociências, Universidade Federal do Rio Grande do Sul, 134p.

Muehe D.H. (org.) 2006. Erosão e Progradação do Litoral Brasileiro. Brasília, Ministério Meio Ambiente, 476 p.

Muehe D. 2001. Critérios Morfodinâmicos para o Estabelecimento de Limites da Orla Costeira para fins de Gerenciamento. Rev. Brasileira de Geomorfologia, 2(1):35-44.

Nicholls R.J. 1995. Synthesis of vulnerability analysis studies. In: Word Coast'93, Proceedings, p. 1-41.

Nimer E. 1979. Climatologia do Brasil. Rio de Janeiro, IBGE, $421 \mathrm{p}$.

Oliveira U.R. 2004. Comportamento morfodinâmico e granulometria do arco praial Pântano do Sul-Açores, Ilha de Santa Catarina,SC, Brasil. Dissertação de Mestrado, Departamento de Geociências, Universidade Federal de Santa Catarina, 102 p.

Perillo G.M.E., Angeles G.R., Piccolo C.1999. Argentina Coast Vulnerability Assessment Built Around GIS. ArcNews on line, fall 99. Disponível em: http://www.esri. com/news/arcnews/fall99articles/34-argentina.html. Acessado em 20/03/2005.

Pernetta J.C \& Milliman J.D. (eds.) 1995. Land and Ocean Interaction in the Coastal Zone: Implementation Plan. SwItzerland, Report IGBP/LOICZ v. 33, 215p.

Porto Filho E. 1993. Sedimentometria e algumas considerações sobre a biogeoquímica dos sedimentos de fundo da Lagoa da Conceição - Ilha de Santa Catarina. Dissertação de Mestrado. Departamento de Geociências, Universidade Federal de Santa Catarina, Florianópolis, 343p.

Richmond B.M., Fletcher C.H., Grossman E.E., Gibbs A.E. 2000. Islands at Risk: Coastal Hazard Assesment and Mapping in the Hawaiian Islands. Environmental Geosciences, 8(1):21-37.

Rosa O.R. \& Herrman M.L. 1986. Geomorfologia. In: Gabinete de Planejamento Estado de Santa Catarina. Atlas de Santa Catarina. Rio de Janeiro, Aerofoto Cruzeiro, p. 31-32.
Silveira J.D. 1964. Morfologia do litoral. In: Azevedo A. (ed.) Brasil: a Terra e o Homem-As Bases Físicas. São Paulo, p. 253-305.

Simó D.H. \& Horn $F^{\circ}$ N.O. 2004. Caracterização e Distribuição Espacial das "Ressacas" e Áreas de Risco na Ilha de Santa Catarina, SC, Brasil. Gravel, 2:93-103.

Souza C.R.G. 1997. As Células de Deriva Litorânea e a Erosão nas Praias do Estado de São Paulo. Tese de Doutoramento. Instituto de Geociências-USP. Volume I (Texto, 184 p.) e Volume II (Anexos, 174 p.).

Souza C.R.G. 2004. Risco a Inundações, Enchentes e Alagamentos em Regiões Costeiras. In: GEDN/UFSC, Simp. Brasileiro de Desastres Naturais, 1, Florianópolis, Anais, p.231-247, CD-Rom.

Souza C.R.G. 2007. Determination of net shore-drift cells based on textural and morphological gradations along foreshore of sandy beaches. Journal of Coastal Research, SI 50:620-625.

Souza C.R.G., Suguio K., Oliveira A.M.S., Oliveira P.E. (orgs.) 2005. Quaternário do Brasil. São Paulo, Ed. Holos, $382 \mathrm{p}$.

Souza C.R.G. \& Suguio K. 2003. The coastal erosion risk zoning and the São Paulo State Plan for Coastal Management. Journal of Coastal Research, SI 35:530-547.

Stive J.F., Aarninkhof H.L., Hanson H., Larson M., Winjnberg K.M., Nicholls R.J., Capobianco M. 2002. Variability of shore and shoreline evolution. Coastal Engineering, 47:211-235.

Suguio K. 1973. Introdução à sedimentologia. São Paulo, T.A. Queiroz, 317 p.

Thumerer T., Jones A. P., Brown D. 2000. A GIS Based Coastal Management System for Climate Change Associated Flood Risk Assesment on the East Coast of England. International Journal of Geographical Information Science, 14(3):265-281.

Titus J.G. \& Richman C. 2001. Maps of lands vulnerable to sea level rise: Modeled elevations along the U.S. Atlantic and Gulf Coasts. Climate Research, 18:205-228.

Varnes D.J. 1984. Landslide Hazard Zonation: Review of Principles and Practice. Paris, UNESCO Press, 56p.

Zang K., Douglas B.C., Leatherman S.P. 2004. Global Warming and Coastal Erosion. Climate Change, 64:41-58.

Zanini L.F.P., Branco P.M., Camozzato E., Ramgrab G.E. (orgs.) 1997. Programa de Levantamentos Geológicos Básicos do Brasil, Folhas Florianópolis/Lagoa, SG. 22Z-D-V/VI, Estado de Santa Catarina, escala 1:100.000. Brasília, DNPM/CPRM, 223 p.

Zuquete L.V., Péjon O.J., Gandolfi N., Paraguassu A.B. 1995. Considerações básicas sobre a elaboração de carta de zoneamentos de probabilidade ou possibilidade de ocorrer eventos perigosos e de riscos associados. Geociências, 14(2):9-39.

Manuscrito ID 9536 Submetido em 19 de outubro de 2007 Aceito em 22 de junho de 2008 Sistema eletrônico de submissão 